\title{
Climate Change, Weather Insurance Design and Hedging Effectiveness
}

\author{
Ines Kapphan ${ }^{\mathrm{a}}$, Pierluigi Calanca ${ }^{\mathrm{b}}$ and Annelie Holzkaemper ${ }^{\mathrm{b}}$ \\ ${ }^{a}$ IED, ETH Zurich, Sonneggstrasse 33, Zurich 8092, Switzerland. \\ E-mail: ikapphan@ethz.ch \\ ${ }^{\mathrm{b}}$ University of Bern, Oeschger Center, Climate Change Research, Switzerland. \\ E-mails: pierluigi.calanca@art.admin.ch; annelie.holzkaemper@art.admin.ch
}

Insurers have relied on historical data to design weather insurance contracts. In light of climate change, we examine the effects of this practice on the hedging effectiveness and profitability of insurance contracts. Using synthetic crop and weather data for today's and future climatic conditions we derive adjusted weather insurance contracts that account for shifts in the distribution of weather and yields. In our scenario, hedging benefits from adjusted contracts almost triple and expected profits increase by about 240 per cent. We further investigate the effect on risk reduction (for the insured) and profits (for the insurer) from hedging future weather risk with non-adjusted contracts based on historical data. In this case, insurers generate profits that are significantly smaller than for adjusted contracts, or even face substantial losses. Moreover, non-adjusted contracts that create higher profits than the adjusted counterparts cause negative hedging benefits for the insured.

The Geneva Papers (2012) 37, 286-317. doi:10.1057/gpp.2012.8

Keywords: weather insurance design; climate change; non-stationarity; hedging effectiveness

\section{Introduction}

Climate change causes shifts in average weather conditions and an increase in the weather variability due to changes in the frequency and occurrence of extreme events. ${ }^{1}$ Some of the extreme weather events that occurred between 2001 and 2010 exceeded already in intensity, duration and geographical extent the most significant historical events on record. ${ }^{2}$ Evidence is mounting that with climate change, the frequency of heatwaves is increasing, for instance, Stott et al., ${ }^{3}$ Beniston, Meehl and Tebaldi, Schär et al., Fischer and Schär. ${ }^{4}$ As a consequence, the return period of events like the pan-European heatwave of 2003 are becoming shorter.

\footnotetext{
${ }^{1}$ According to IPCC (2007), it is very likely (90-99 per cent probability) that there will be higher maximum temperatures, more hot days, higher minimum temperatures, fewer cold days and more intense precipitation events over many land areas. It is likely (67-90 per cent probability) that there will be increased summer drying over most mid-latitude continental interiors and associated risk of drought.

${ }^{2}$ WMO (2011).

${ }^{3}$ Stott et al. (2004) find an increased probability of hot summers like the 2003 heatwave. Stott et al. (2004) state that it is very likely that human influence on climate has doubled the current risk of a heatwave such as the one that occurred in 2003, compared to pre-industrial times.

${ }^{4}$ Beniston (2003), Meehl and Tebaldi (2004), Schär et al. (2004), Fischer and Schär (2010).
} 
Agricultural production, as well as many other industrial sectors, is sensitive to changes in climatic conditions. An increase of prolonged drought-like conditions, caused by higher temperatures or more frequent heatwaves, has implications for the productivity of the agricultural sector. Scientific evidence, showing that climate change shifts the mean and variance of crop yields, is accumulating. The effect of changes in climatic variables on mean crop yields has been studied widely. ${ }^{5}$ The year-to-year change in climatic conditions is found to be a major determinant of crop yield fluctuations. ${ }^{6,7}$ Climate change thus makes agricultural production more risky, ${ }^{8}$ and without risk management less profitable. ${ }^{9}$ Consequently, agricultural insurance solutions become more important to protect against a climate change induced increase in weather-related losses.

The changing occurrence and frequency of extreme weather events implies, however, that historical return periods underestimate the likelihood of agricultural losses in the future. In the context of water-resource risk management, Milly et al. ${ }^{10}$ were the first to note that "climate change undermines a basic assumption that historically has facilitated management of [...] risks". Risk analysis and management relied on the assumption that distributions are stationary over time in order to estimate return periods of weather-related events. ${ }^{10}$ In the context of agriculture, McCarl et al. ${ }^{11}$ examine historical crop yield data and find that the stationarity assumption is no longer valid. McCarl et al. ${ }^{11}$ conclude that risk analysis in light of climate change requires to use distributions with non-stationary means and variances along with possibly shifting higher order moments. In conclusion, future agricultural losses cannot be predicted any longer by extrapolating historical trends of weather and yield data.

Insurers have historically provided insurance solutions for weather-related losses, and are going to play an integral role for society to cope with the consequences of climate change. Weather-related insurance losses have increased in recent years, according to Mills, ${ }^{12}$ much faster than non-weather related events. ${ }^{13}$

${ }^{5}$ Reilly et al. (2002); Deschenes and Greenstone (2007); Schlenker and Roberts (2009).

${ }^{6}$ Mearns et al. (1992) investigate how climate variability affects agricultural production. The authors find that increases in variability of temperature and precipitation result in significant increases in yield variability and that precipitation changes have an even more pronounced effect.

${ }^{7}$ Olesen and Bindi (2002); Chen et al. (2004); Isik and Devadoss (2006); McCarl et al. (2008).

${ }^{8}$ IPCC $(2001,2007)$.

${ }^{9}$ The pan-European heatwave of 2003 caused, for example, uninsured crop losses of around USD 12.3 billion (Schär and Jendritzky, 2004).

${ }^{10}$ Milly et al. (2008) define stationarity as follows: "Stationarity is the idea that natural systems fluctuate within an unchanging envelope of variability. Stationarity implies that any variable has a time-invariant (or a one year periodic) probability density function, whose properties can be estimated from the instrument record".

${ }^{11}$ McCarl et al. (2008).

12 According to Mills (2005), insurers' weather-related loss models focus on catastrophic events, and lossfrequency curves are predicted on extrapolating historical trends.

13 According to Munich Re (2005), weather-related insurance costs have risen continuously (from 1950 to 2005). 
The insurance industry has started to pay attention to the implications of climate change for their business. ${ }^{14}$ Traditionally, insurers have used historical data to design and price insurance products. ${ }^{12}$ However, as noted by Hawker ${ }^{15}$ "a changing climate has the potential to reduce the insurance industry's capacity to calculate, price, and spread weather-related risk". Therefore, according to Mills ${ }^{16}$ "insurers' traditional modeling techniques are ill-suited for understanding the implications of climate change ...". Only within natural catastrophe modelling, insurers started to couple climate models with catastrophe models to examine the financial implications of climate change on insured risk. ${ }^{17}$ The impact of climate change on other insurance lines, such as index-based weather insurance, however, remains to be demonstrated. The aim of this paper is to fill in this gap.

The literature examining the link between climate change and insurance focuses on damage-based forms of weather insurance, such as property and liability insurance. ${ }^{18}$ For damage-based insurance products, climate change implies that new extreme events may occur that cause damages, which exceed the extent of previously known damages, and in addition the frequency of weather-related losses is increasing. ${ }^{19}$ These studies share the view that if weather-related insurance losses continue to rise, insurers will need to respond by increasing premiums, possibly restricting coverage and increasing deductibles for their damage-based weather insurance products. Less attention has been devoted to climate change and parametric weather insurance, which is the focus of this work. ${ }^{20}$

Index-based weather insurance is attractive from the perspective of insurers since no uncertainty regarding the extent of payments (i.e. the losses for the insurer) exists. The payoff structure defines the range of all possible payments. Climate change only affects the uncertainty of incorrectly estimating the underlying weather (index) distribution and thus charging an inadequate premium. For the insured, however, this implies that losses beyond the maximum payment are not insured. In contrast to damage-based insurance, the risk reduction of parametric weather insurance depends on the weather distribution (by affecting the premium) and on the payoff structure, which determines the indemnity for given realisations of the underlying weather index. With this in mind, we also aim at shedding light on the consequences of using historical data for designing and pricing parametric weather insurance products with respect to risk reduction.

${ }^{14}$ Lloyds of London (2006); Hawker (2007); Clemo (2008); Dlugolecki (2008); Maynard (2008); Mills (2009).

${ }^{15}$ Hawker (2007).

16 Mills (2009).

${ }^{17}$ Bresch et al. (2000); ABI (2009); Wuest et al. (2011).

${ }^{18}$ Clemo (2008); Ward et al. (2008).

${ }^{19}$ Damage-based insurance products indemnify the insured for weather-related losses based on an inspection of the loss. The insured is thus guaranteed an indemnification according to the terms of the contract and the insurance product thus delivers the desired risk reduction. Uncertainty about the extent and frequency of losses is borne by the insurer.

${ }^{20}$ Parametric insurance, such as index-based weather insurance, indemnifies the insured based on the realisation of an exogenous, verifiable weather event. 
The objective of this paper is twofold. First, we determine the potential for weather insurance in light of climate change. To do so, we evaluate the benefits from hedging weather risk given today's climatic condition, and compare them to the benefits from hedging weather risks with adjusted insurance contracts in a warming and more volatile future climate. An adjusted insurance contract explicitly takes the expected changes in the mean and variability of both weather and crop yields into account. To design an adjusted weather insurance contract, we use simulated (forward-looking) weather and yield data representing a possible climate change scenario.

Second, we assess the effect on risk reduction from hedging weather risk in a changing climate with non-adjusted weather insurance contracts. Non-adjusted insurance contracts are designed and priced using historical (backward-looking) data. For the prevailing climatic conditions, non-adjusted contracts are mis-designed, which affects the insured since the payoff structure does not offer the protection required to compensate the actual losses, and mispriced, which has consequences for the insurer, who may face unexpected payouts.

We use a process-based crop simulation model to derive maize yields for today's and future climatic conditions. In particular, we use simulated maize yields for Schaffhausen (SHA, latitude: 47.69, longitude: 8.62), Switzerland, that are derived with a process-based crop simulation model, for the current climatic conditions (19812001), and for an Intergovernmental Panel on Climate Change (IPCC) A2 emission scenario reflecting climatic conditions around 2050.

To derive weather insurance contracts, we simulate the payoff structure using the method developed by Kapphan. ${ }^{21}$ Other methodologies for deriving weather insurance contracts exist and could be used in general to address the research questions outlined here. We use the model by Kapphan ${ }^{21}$ since the resulting contracts are designed to yield optimal hedging effectiveness for the insured, or maximal profits for the insurer. The optimal contracts are derived by non-parametrically estimating yield distributions conditional on weather and maximising the expected utility of the insured, or by maximising expected profits for the insurer. Optimal weather insurance contracts are characterised by a non-linear payoff structure (for the entire range of weather realisations).

Given the insurance contracts, we evaluate the benefits from hedging weather risk for today's climate by using an insurance contract that has been simulated for today's conditions and then compare the findings with the benefits from hedging weather risk in a future climate. To account for the increase in the weather and yield variability due to climate change, we apply the insurance contract that has been derived using future (projected) yield and weather data to future weather conditions. This comparison sheds light on the potential of using weather insurance to hedge weather risks in a changing climate under the assumption that insurers account for the non-stationarity of the underlying weather and yield distributions. We find that, with climate change, the benefits from hedging with adjusted contracts almost

${ }^{21}$ Kapphan (2011). 
triple, and that expected profits increase by about 240 per cent (depending on the contract).

To address our second research question, we use insurance contracts that are designed for today's climate and evaluate the risk reduction that can be achieved with them in a future climate, that is we determine the risk reduction of non-adjusted insurance contracts. By comparing the risk reduction of non-adjusted contracts with the benefits from adjusted insurance contracts, we quantify for the first time the effect of not adapting insurance contracts on risk reduction (expected profits) for the insured (the insurer). Our results indicate that insurers may either face substantial losses or generate profits that are significantly smaller than profits from offering adjusted insurance contracts. While our numerical results are crop- and location-specific, our approach for evaluating the potential of parametric weather insurance in a changing climate and for assessing the consequences of offering non-adjusted contracts can be applied to any crop or location for which sufficient data (for calibrating a process-based crop model) exists.

A large strand of literature exists that examines the potential of index-based weather insurance to hedge agricultural yield risk using historical weather and yield data. ${ }^{22}$ By using simulated weather and yield data, we follow Torriani et al. ${ }^{23}$ who first used climate change data to analyse the benefits from hedging drought risk in today's and future climatic conditions. The idea to use "forward-looking risk models that take climate change into account" is supported, for instance, by Mills. ${ }^{16}$ We extend the work by Torriani et al. ${ }^{23}$ in two aspects. First, we use an optimal weather insurance model to simulate the payoff structure and to determine the hedging benefits for the insured, as well as the expected profits for the insurer, under both climates. Second, and more importantly, we compare for the first time the benefits from hedging future weather risk with an adjusted contract to the risk reduction from a non-adjusted contract.

\section{Theoretical approach}

We use the model developed by Kapphan ${ }^{21}$ to numerically derive the payoff structure of an index-based weather insurance with optimal hedging effectiveness for today's and future climatic conditions. For the numerical analysis, we consider five time periods with different climatic conditions, indexed by $c$. In each climate scenario, the insured is faced with a stochastic revenue $y \in \mathcal{Y}_{c} \equiv\left[\underline{y}_{c}, \bar{y}_{c}\right] .{ }^{24}$ We assume for the moment that $c$ only represents either today's, $t$, or future climatic conditions, $f$, that is $c=\{t, f\} .{ }^{25}$ Then, for a given climate scenario $c$, yields in a given year $i$ are represented by $y_{c, i}$ and $z_{c, i}$ represents the corresponding realisation of a weather index. The influence of weather on yields under given climatic conditions is captured

${ }^{22}$ Barnett and Vedenov (2004); Breustedt et al. (2008); Musshoff et al. (2009); Berg et al. (2009); Leblois and Quirion (2011).

${ }^{23}$ Torriani et al. (2007a).

${ }^{24}$ The insured generates revenue solely from selling the production output. An average price is used to compute the revenue and production costs are not considered in this framework.

${ }^{25}$ In the section "Hedging effectiveness and expected profits of non-adjusted contracts", we add three more climatic scenarios that represent the transition period, so that in total five periods are analysed. 
through the conditional distribution of yields with $\operatorname{cdf} F_{c}(y \mid z)$ with density $f_{c}(y \mid z)$. The distribution of the weather index, $z \in \mathcal{Z}_{c} \equiv\left[\underline{z}_{c}, \bar{z}_{c}\right]$ is characterised by the cdf $G_{c}(z)$ and density $g_{c}(z)$. Following Kapphan, ${ }^{21}$ the conditional distribution of yields $F_{c}(y \mid z)$ and the cdf of the weather index $G_{c}(z)$ are estimated non-parametrically using a Gaussian kernel function.

To derive the optimal weather insurance payoff structure $p_{c}(z)$ the insured's expected utility is maximised subject to the constraint that risk-neutral insurers charge an actuarially fair premium for the contract. ${ }^{26}$ The insured is risk-averse and has preferences over consumption, $\theta$, with $\theta=y+p_{c}(z)$, which are characterised by constant relative risk aversion, that is $u(\theta)=\left(\theta^{1-\sigma}\right) /(1-\sigma)$ with $\sigma>0 .{ }^{27}$ Formally, $p_{c}^{*}(z)$ solves the expected utility of the insured

$$
\max _{p_{c}(z)} \int_{\mathcal{Z}_{c}} \int_{\mathcal{Y}_{c}} u\left(y+p_{c}(z)\right) d F_{c}(y \mid z) d G_{c}(z)
$$

subject to the constraint

$$
\int_{\mathcal{Z}_{c}} p_{c}(z) d G_{c}(z)=0 .
$$

Constraint (2) implies that insurers make on average zero profits, which is a widely used method, known as the "burn rate" method, to price insurance contracts. The premium $P$ is then determined by the minimum of the net-payment function $p_{c}^{*}(z)$.

Solving (1) subject to (2) with today's conditional yield cdf, $F_{t}(y \mid z)$, and the cdf of today's weather index, $G_{t}(z)$, yields $p_{t}^{*}(z)$. To obtain the optimal weather insurance contract for future climatic conditions $p_{f}^{*}(z)$, the optimisation problem is solved analogously with $F_{f}(y \mid z)$, and $G_{f}(z)$, which are obtained from simulated weather and yield data that takes climate change into account. In reality, the insurer may add a mark-up on fair premiums to cover additional costs associated with offering weather insurance. In order to determine to which extent fair contracts can be loaded such that the insured still finds the contract attractive, we also derive insurance contracts that maximise the insurer's profit. Formally, for given climatic conditions, $c$, the profitmaximising insurance contract $\tilde{p}_{c}^{*}(z)$ is derived by solving

$$
\max _{\tilde{p}_{c}(z)} \Pi_{c} \equiv-\int_{\mathcal{Z}_{c}} \tilde{p}_{c}(z) d G_{c}(z)
$$

${ }^{26} p(z)$ represent the net-insurance payments, that is the difference between the premium, $P$, and the insurance indemnity.

${ }^{27}$ To numerically derive the optimal insurance contract, we use a moderate coefficient of relative risk aversion, that is $\sigma=2$. For explorations of how $\sigma$ affects the shape of the optimal weather insurance contract, see Kapphan (2011). 
subject to the constraint that the insured's expected utility is equal to or greater than his expected utility in an uninsured situation, that is

$$
\int_{\mathcal{Z}_{c}} \int_{\mathcal{Y}_{c}} u\left(y+\tilde{p}_{c}(z)\right) d F_{c}(y \mid z) d G_{c}(z) \geqslant \int_{\mathcal{Z}_{c}} \int_{\mathcal{Y}_{c}} u(y) d F_{c}(y \mid z) d G_{c}(z) .
$$

Maximum loading factors (in per cent) are then determined by comparing the premium of the optimal (zero-profit) contract $P$ with the premium of the profitmaximising contract $\tilde{P} .{ }^{21}$ By deriving both the optimal (zero-profit) insurance contract and the profit-maximising contract, the range of insurance contracts that could feasibly be traded is fully characterised.

To quantify the risk reduction potential of an optimal insurance contract, we compute the percentage increase of all income realisations in the situation without insurance that makes farmers equally well-off (in expected utility terms) as in the situation with insurance. ${ }^{21}$ Formally, this percentage increase $\delta_{c}\left(p_{c}\right)$ solves

$$
\int_{\mathcal{Z}_{c}} g_{c}(z) \int_{\mathcal{Y}_{c}} f_{c}(y \mid z) \frac{\left(p_{c}(z)+y\right)^{1-\sigma}}{1-\sigma} d y d z=\int_{\mathcal{Z}_{c}} g_{c}(z) \int_{\mathcal{Y}_{c}} f_{c}(y \mid z) \frac{\left(\left(1+\delta_{c}\left(p_{c}\right)\right) y\right)^{1-\sigma}}{1-\sigma} d y d z
$$

with solution:

$$
\delta_{c}\left(p_{c}\right)=\left(\frac{\int_{\mathcal{Z}_{c}} g_{c}(z) \int_{\mathcal{Y}_{c}} f_{c}(y \mid z)\left(p_{c}(z)+y\right)^{1-\sigma} d y d z}{\int_{\mathcal{Z}_{c}} g_{c}(z) \int_{\mathcal{Z}_{c}} f_{c}(y \mid z) y^{1-\sigma} d y d z}\right)^{\frac{1}{1-\sigma}}-1
$$

Thus, $\delta_{c}\left(p_{c}\right)$ measures the insured's value of weather insurance for a given optimal insurance contract $p_{c}$ and given climatic conditions $c$.

For the insurer, we determine the expected profit from offering a profit-maximising insurance contract for given climatic conditions as follows:

$$
\Pi_{c}\left(\tilde{p}_{c}\right)=-\int_{\mathcal{Z}_{c}} \tilde{p}_{c}(z) d G_{c}(z)
$$

By construction, the benefits from hedging with a profit-maximising contract for the insured, $\delta_{c}\left(\tilde{p}_{c}\right)$, and the expected profits for an optimal insurance contract, $\Pi_{c}\left(p_{c}\right)$, are zero. The benefits from hedging with an optimal (zero-profit) insurance contract for today's climatic conditions, $\delta_{t}\left(p_{t}\right)$, are derived by evaluating the risk reduction in today's climate, $\delta_{t}$, using an optimal contract $p_{t}(z)$ that has been derived using today's yield and weather data. The benefits from hedging weather risk in the future with an optimal contract, $p_{f}(z)$, that is designed with weather and yield data that accounts for the changed weather and yield distributions, is then given by $\delta_{f}\left(p_{f}\right)$.

Comparing $\delta_{f}\left(p_{f}\right)$ with $\delta_{t}\left(p_{t}\right)$ allows us to quantify the benefits from using adjusted weather insurance contracts to cope with future weather risk (for the insured). 
Table 1 Notation for profits and deltas from adjusted and non-adjusted contracts

\begin{tabular}{llccc}
\hline Climate & Contract & & Profits & Delta \\
\hline $\begin{array}{l}\text { Today } \\
\text { Adjusted }\end{array}$ & & & & \\
& Optimal & $p_{t}$ & 0 & $\delta_{t}\left(p_{t}\right)$ \\
& Profit-maximising & $\tilde{p_{t}}$ & $\Pi_{c}\left(\tilde{p}_{t}\right)$ & 0 \\
Future & & & \\
Adjusted & Optimal & $p_{f}$ & 0 & $\delta_{f}\left(p_{f}\right)$ \\
Non-adjusted & Profit-maximising & $\tilde{p}_{f}$ & $\Pi_{c}\left(\tilde{p}_{f}\right)$ & 0 \\
& Optimal & $p_{t}$ & $\Pi_{f}\left(p_{t}\right)$ & $\delta_{f}\left(p_{t}\right)$ \\
& Profit-maximising & $\tilde{p}_{t}$ & $\Pi_{f}\left(\tilde{p}_{t}\right)$ & $\delta_{f}\left(\tilde{p_{t}}\right)$ \\
\hline
\end{tabular}

Note: Insurer's profit $\left(\Pi_{c}\right)$ and insured's benefit $\left(\delta_{c}\right)$ in a given climate scenario $(c=t, f)$ depend on the contract type $\left(p_{c}\right.$, or $\tilde{p}_{c}$ ), and the climatic condition for which the contract was designed (for $c$, or $c-1$ ). If contract $p_{c}$, or, respectively, $\tilde{p}_{c}$, is used for risk reduction in the climate scenario $c$, then $\delta_{c}\left(p_{c}\right)$ represents the risk reduction of an adjusted, optimal contract. $\delta_{c}\left(\tilde{p}_{c}\right)$ represents the risk reduction from an adjusted, profitmaximising contract. $\delta_{c}\left(p_{c-1}\right)$ represents the risk reduction of an optimal, non-adjusted contract. $\delta_{c}\left(\tilde{p}_{c-1}\right)$ represents the risk reduction of a profit-maximising, non-adjusted contract.

Similarly, by comparing $\Pi_{t}\left(\tilde{p_{t}}\right)$ with $\Pi_{f}\left(\tilde{p_{f}}\right)$, we quantify the profitability of offering weather insurance in light of climate change.

The risk reduction of a non-adjusted, optimal insurance contract is then given by $\delta_{f}\left(p_{t}\right)$, and $\Pi_{f}\left(p_{t}\right)$ measures the expected profits from offering non-adjusted, optimal insurance contract with climate change. ${ }^{28} \mathrm{We}$ also derive the expected profits for the insurer if he continues to offer today's profit-maximising contract with climate change, $\Pi_{f}\left(\tilde{p_{t}}\right)$, that is if the today's profit-maximising contract is not adjusted over time. Similarly, we evaluate the hedging effectiveness of today's profit-maximising contract with climate change, $\delta_{f}\left(\tilde{p_{t}}\right)$.

By comparing $\Pi_{f}\left(\tilde{p}_{f}\right)$ with $\Pi_{f}\left(\tilde{p_{t}}\right)$, we evaluate the effect of offering non-adjusted insurance contracts on expected profits. Similarly, by comparing $\delta_{f}\left(p_{f}\right)$ with $\delta_{f}\left(p_{t}\right)$, the effect of hedging with non-adjusted weather insurance contracts for the insured is quantified. Table 1 provides an overview of the notation and the different comparisions outlined.

\section{Data and climate change simulations}

To derive maize (Zea mays $L$. ) yield data for today's climatic conditions and a climate scenario, we follow Torriani et al..$^{29}$ and use a process-based crop simulation model in connection with a weather generator to simulate 1,000 yield realisations for each climate scenario. Synthetic weather data needed as input, was generated with the stochastic weather generator LARS-WG. ${ }^{30}$ Observed daily weather data collected

\footnotetext{
${ }^{28}$ If an optimal insurance contract is offered in climatic conditions that are different from the ones used to design and price the contract, $\Pi_{f}\left(p_{t}\right)$, is not necessarily equal to zero.

29 Torriani et al. (2007a, b).

${ }^{30}$ Semenov (1997).
} 
between 1981 and 2010 at Schaffhausen (latitude: $47.69 \mathrm{~N}$, longitude: $8.62 \mathrm{E}$ ), Switzerland, was used to condition LARS-WG, and baseline statistics were modified according to a climate change scenario to generate daily weather series representing future climatic conditions.

As for the climate change scenario (2036-2065), we refer to the same data as used by Lazzarotto et $a .^{31}$ and Finger et al., ${ }^{32}$ that is regional projections for Europe developed by Vidale et $a .^{33}$ with the Climate High Resolution Model (CHRM) regional model in the framework of the PRUDENCE project ${ }^{34}$ on the basis of an A2 emission scenario. ${ }^{35}$ In practice, differences in monthly averages for the length of wet and dry spells, total rainfall, daily minimum and maximum temperature, and daily totals of solar radiation were first inferred for the time span between 1961-1990 and 2071-2100 originally addressed by PRUDENCE. The differences were then re-scaled in time to yield a corresponding climate change signal for our baseline (1981-2010) and selected future time window (2036-2065).

The synthetic daily weather data feeds into the process-based crop model CropSyst ${ }^{36}$ for maize. CropSyst is a deterministic crop physiological growth model that simulates crop yields for given environmental and management conditions. The calibration for maize is based on Torriani et $a .^{29}$ and was adapted for the newer CropSyst version 4.13.09. ${ }^{37}$ Process-based crop simulation models are widely used to study the response of plants to climate change and to evaluate possible adaption options. $^{38}$

For the purpose of this study, three additional weather and yield scenarios were created using weighted random drawings from today's and 2050's weather series. Weights of 75 per cent and 25 per cent (today and future), 50 per cent and 50 per cent, and 25 per cent and 75 per cent were assumed to create interim scenarios. ${ }^{39}$ Table 2 summarises the notation for the interim scenarios and the interpolation weights used for their creation. These interim scenarios cannot be related to particular years between today and 2050, since the climate system may not change linearly from today's conditions to the projected climate around 2050.

Table 3 summarises the statistical moments of the simulated maize data for the baseline and the four climate scenarios. Average maize yields decrease from 9,266 kilo per hectare $(\mathrm{kg} / \mathrm{ha})$ under today's climatic conditions to $8,190 \mathrm{~kg} / \mathrm{ha}$ for the full 2036-2065 climate change scenario. At the same time, the standard deviation (std) increases from $1,456.5$ to $2,105.7 \mathrm{~kg} / \mathrm{ha}$, with a corresponding increase in the coefficient of variation from 0.157 to 0.257 . Overall, we observe that mean yields decrease

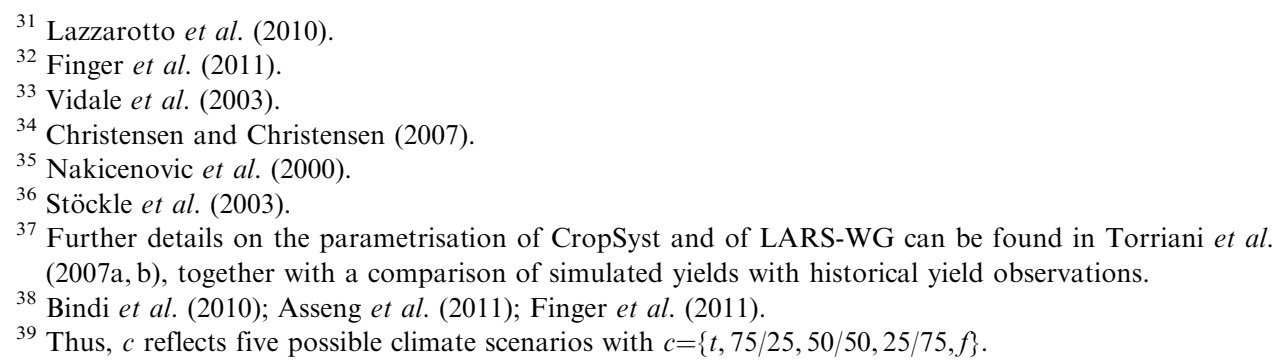


Table 2 Climatic interim scenarios

\begin{tabular}{lccccc}
\hline $\begin{array}{l}\text { Climatic } \\
\text { scenarios }\end{array}$ & $\begin{array}{c}\text { Today } \\
1981-2001\end{array}$ & $\begin{array}{c}\text { Scenario } 1 \\
\text { Moderate }\end{array}$ & $\begin{array}{c}\text { Scenario 2 } \\
\text { Medium }\end{array}$ & $\begin{array}{c}\text { Scenario 3 } \\
\text { Strong }\end{array}$ & $\begin{array}{c}\text { Future } \\
2036-2065\end{array}$ \\
\hline Weights $(\mathrm{t} \% / \mathrm{f} \%)$ & $100 / 0$ & $75 / 25$ & $50 / 50$ & $25 / 75$ & $0 / 100$ \\
Contracts & $p_{t}\left(z_{t}\right)$ & $p_{75 / 25}(z)$ & $p_{50 / 50}(z)$ & $p_{25 / 75}(z)$ & $p_{f}\left(z_{f}\right)$ \\
\hline
\end{tabular}

Note: Interim scenarios for both weather and yields are created by interpolation of today's and future data. $t \%$ is the percentage of data used from today's yield and weather distribution, and $f \%$ is the percentage of data drawn from the simulated weather and yield distribution for the 2036-2065 climate scenario.

Table 3 Descriptive analysis of simulated maize yields

\begin{tabular}{lccccc}
\hline $\begin{array}{l}\text { Climatic } \\
\text { Scenarios }\end{array}$ & $\begin{array}{c}\text { Today } \\
\text { 1981-2001 }\end{array}$ & $\begin{array}{c}\text { Scenario 1 } \\
\text { Moderate }\end{array}$ & $\begin{array}{c}\text { Scenario 2 } \\
\text { Medium }\end{array}$ & $\begin{array}{c}\text { Scenario 3 } \\
\text { Strong }\end{array}$ & $\begin{array}{c}\text { Future } \\
\text { 2036-2065 }\end{array}$ \\
\hline Mean (kg/ha) & 9266 & 9038 & 8762 & 8449 & 8190 \\
Std (kg/ha) & 1456 & 1681 & 1885 & 2022 & 2105 \\
CV & 0.157 & 0.186 & 0.215 & 0.239 & 0.257 \\
Skewness & -0.6881 & -0.5992 & -0.2615 & -0.0042 & 0.1840 \\
\hline
\end{tabular}

Note: Evolution of maize yield statistics for Schaffhausen over time.
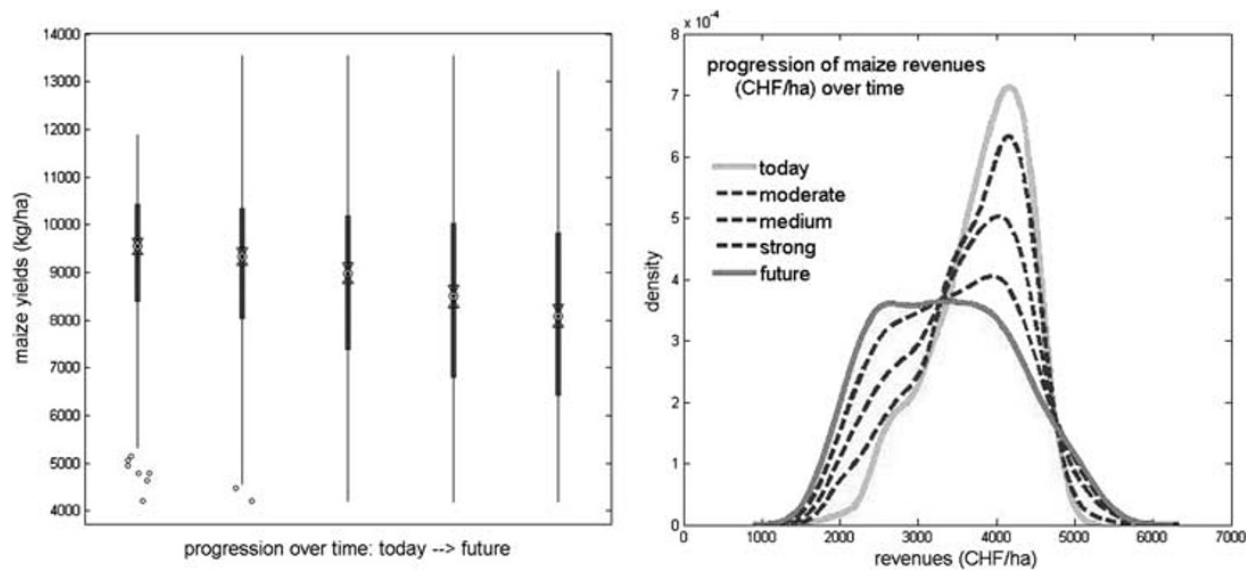

Figure 1. Evolution of the maize yield (left) and revenue distribution (right) over time.

and maize production is becoming more risky. These tendencies can also be inferred from Figure 1 (left), which shows the boxplots for the five yield distributions, and the change in the revenues from maize production (right). ${ }^{40}$ Hence, without adaptation, maize production is not only becoming less profitable, but also more risky over time.

${ }^{40}$ Revenues from maize production are derived by multiplying crop yields with the average price for maize from 2006 to 2009, which was $41.00 \mathrm{CHF} / 100 \mathrm{~kg}$ (SBV, 2010). Production costs are not considered. 


\section{Weather index design}

The core assumption underlying weather insurance is that there exists a co-variate relationship between crop yields and the underlying weather index. The design of an index-based weather insurance product thus involves identifying a weather index that predicts crop yields well. Since plant development is affected throughout the growing phase by various weather events, multi-peril weather indices tend to predict crop yields better than single weather events (such as cumulated precipitation or mean temperature). To account for the fact that with climate change phenology phases occur earlier in the season, weather variables are derived at each phenology phase for both climatic scenarios $(c, f)$. Phenology stages are estimated based on growing degree days (GDDs), the sowing date, and the number of GDDs needed to complete each phenology phase. For maize, four phenology phases are distinguished: emergence, vegetative period, grain filling and maturity. The following variables are derived at each phenology phase: averages of maximum and minimum temperatures, mean precipitation, the moisture availability to the plant, and the potential evapotranspiration. Multivariate regressions are performed to identify weather events that explain a large fraction of the maize yield variability in both climates. The estimated coefficients are then used to construct weather indices. For a detailed overview and derivation of the weather indices used in this study, see Kapphan et al. ${ }^{41}$

For the purpose of the study, four weather indices are selected-single as well as multi-peril indices - that offer risk protection for different weather phenomena and vary in their goodness of fit. Since precipitation is found to be a major driver of maize growth in Schaffhausen, all indices use precipitation as an input. ${ }^{42}$ Index 1 uses mean precipitation during the vegetative period of maize growth to measure the water supply, and explains 37.0 per cent of the yield variability in today's climatic conditions, and 39.2 per cent with climate change. Considering in addition the influence of heat stress, as measured by the average maximum temperatures during the grain filling period, Index 2 explains 50.3 per cent, and with climate change 68.3 per cent. Index 3 measures the actual water availability, that is the difference between mean precipitation and potential evapotranspiration, and explains 46.3 per cent, and 67.8 per cent in the climate change scenario, of the yield variability. Taking the influence of multiple weather events at different phenology stages into account, Index 4 explains the largest fraction of the yield variability with 62.2 per cent, and 74.5 per cent. All weather indices represent predicted yields (measured in $\mathrm{kg} / \mathrm{ha}$ ), and are converted into predicted revenues (in $\mathrm{CHF} / \mathrm{ha}$ ) using the crop price of $0.41 \mathrm{CHF} / \mathrm{kg}$ for maize $(\mathrm{CHF} / \mathrm{kg}){ }^{43}$

For all indices, we observe that with climate change the effect of weather on maize yields increases, that is a larger fraction of maize yields is explained by weather, which implies that the potential for hedging yield risk with weather-based insurance products improves. Table 4 summarises the Spearman correlation coefficients and adjusted

\footnotetext{
${ }^{41}$ Kapphan et al. (2011).

42 Precipitation enters either directly as an average (as in Index 2), or indirectly via the computation of potential evapotranspiration (as in Index 3), or for deriving the moisture deficit measure (as in Index 4).

43 The average price for maize from 2006 to 2009 in Switzerland, which was $41.00 \mathrm{CHF} / 100 \mathrm{~kg}$ (SBV, 2010).
} 
Table 4 Descriptive statistics of weather indices

\begin{tabular}{llcccc}
\hline & In percentage & Index 1 & Index 2 & Index 3 & Index 4 \\
\hline Today & Corr & 60.8 & 70.9 & 68.1 & 78.9 \\
& Adj. $R^{2}$ & 37.0 & 50.3 & 46.3 & 62.2 \\
Future & & & & 82.3 & 86.3 \\
& Corr & 62.6 & 82.6 & 67.8 & 74.5 \\
\hline
\end{tabular}

Note: Today's weather indices are selected based on the Spearman rank correlation coefficient (Corr) and the adjusted $R$-square (adj. $R^{2}$ ) from the weather-yield regression for today's conditions. Future weather indices are constructed using the same weather variables, measured during future phenology phases, and using the coefficients from future weather-yield regressions as weights.
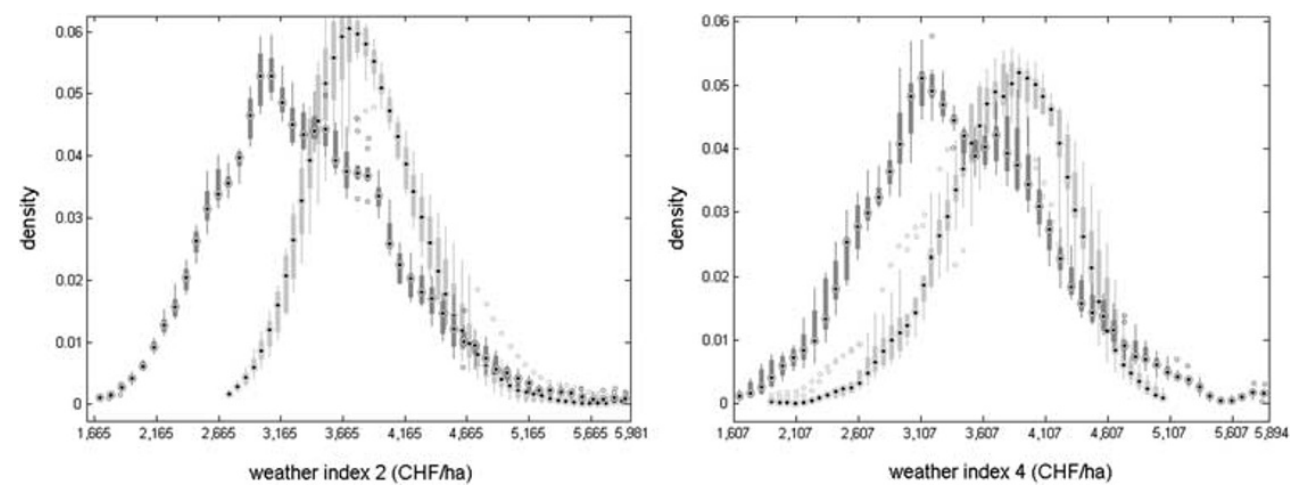

Figure 2. Densities of weather Indices 2 and 4 for the baseline (light) and future scenario (dark). Estimates of the mean and standard deviation at each realisation of the weather index are shown as boxplots.

$R$-square of the four weather indices for the baseline and the future scenario. Figure 2 shows the densities of Indices 2 and 4 for both the baseline and the future scenario. We observe a leftward shift of all index densities, which is caused by a decrease in precipitation in our climate scenario.

We derive interim scenarios for the weather indices (predicted yields) by interpolating the distributions $g_{t}(z)$ and $g_{f}(z)$ in the same manner as for crop yields (see section "Data and climate change simulations"). As with crop yields, we observe over time a decrease in mean index values, and a widening of the standard deviation over time for all indices.

\section{Results: adjusted weather insurance contracts}

\section{Comparison of optimal contracts today and with climate change}

We start by comparing the optimal adjusted weather insurance contract for today's conditions, $p_{t}$, with the optimal adjusted contract for future conditions, $p_{f}$. The shape 


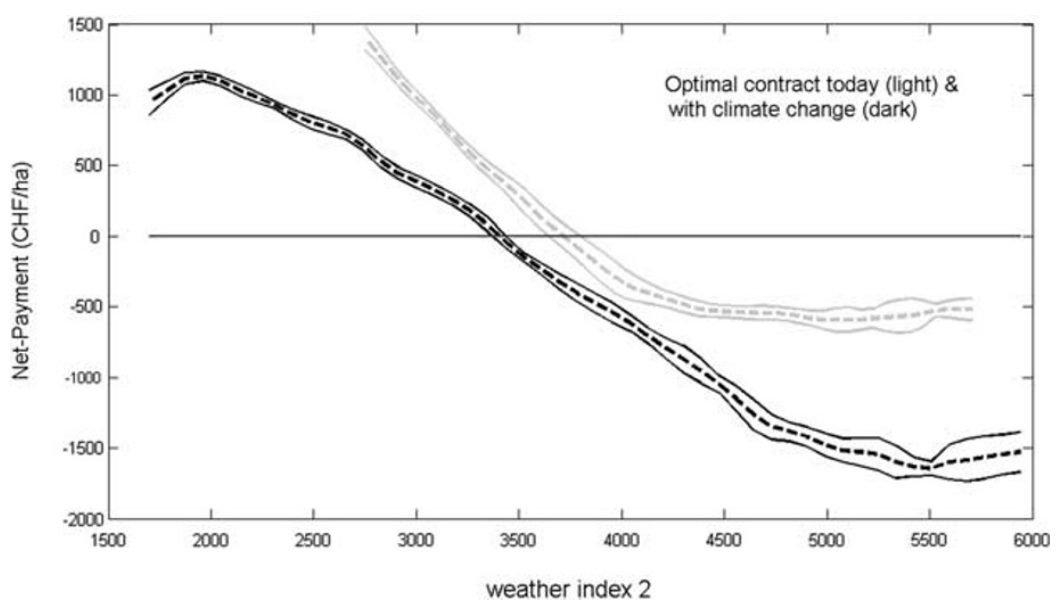

Figure 3. Optimal contracts (dashed line) for Index 2 with standard deviation (solid lines) for the baseline (light) and the future scenario (dark).

of the optimal contracts, $p_{t}$ and $p_{f}$, reflects the changes in the riskiness of the respective conditional yield distributions, as explained in Kapphan, ${ }^{21}$ and is non-linear for the entire range of weather realisations. All optimal contracts pay out for low values of the weather index, and have negative net-payments (corresponding to a premium payment) for very high values of the index. At the point where the net-payment is equal to zero, the insured fully recovers the premium. The minimum of the payoff function defines the premium. ${ }^{44}$

Figure 3 shows the optimal weather insurance contract for Index 2 for today's and future climatic conditions. ${ }^{45}$ We obtain estimates of the standard deviation for $p_{c}(z)$ (at each realisation of $z$ ) by ten times randomly drawing 900 observations with replacement from the data, and solving (1) subject to (2) as described in the section "Theoretical approach". ${ }^{46}$ The standard deviation of $p_{t}$ for moderate $z$ is on average equal to $68.7 \mathrm{CHF} / \mathrm{ha}$, and with climate change, $\operatorname{std}\left(p_{f}\right)$ is on average equal to $67.9 \mathrm{CHF} /$ ha. The standard deviation of $p_{t}$ and $p_{f}$ increases only for very extreme realisations of the weather index, that is $\operatorname{std}\left(p_{t}\right)=119.2 \mathrm{CHF} / \mathrm{ha}$, and respectively, $\operatorname{std}\left(p_{f}\right)=150.3 \mathrm{CHF} / \mathrm{ha}$, that is for very high and rare weather events. Our method for simulating optimal weather insurance contracts thus produces robust results.

As pointed out in the previous section, the density of the weather index, $g_{c}(z)$, shifts to the left with climate change, which is due to a decrease in precipitation during the growing season. In addition, the weather density widens with climate change (i.e. from $c=t$ to $c=f$ ), which is due to an increase in the number of drought-like weather events.

44 The gross-payoff function can be obtained by adding the premium to each net-payment. The maximum payment of the optimal gross-payoff function can be interpreted as the cap of a stylised weather derivative contract.

45 The results described for Index 2 are similar for the other indices, see Kapphan et al. (2011).

${ }^{46}$ This procedure is also used to obtain estimates for the standard deviation of the risk reduction, as measured by $\delta_{c}$, and the expected profits, as measured by $\Pi_{c}$, discussed in sections 5.2 to 5.3. 


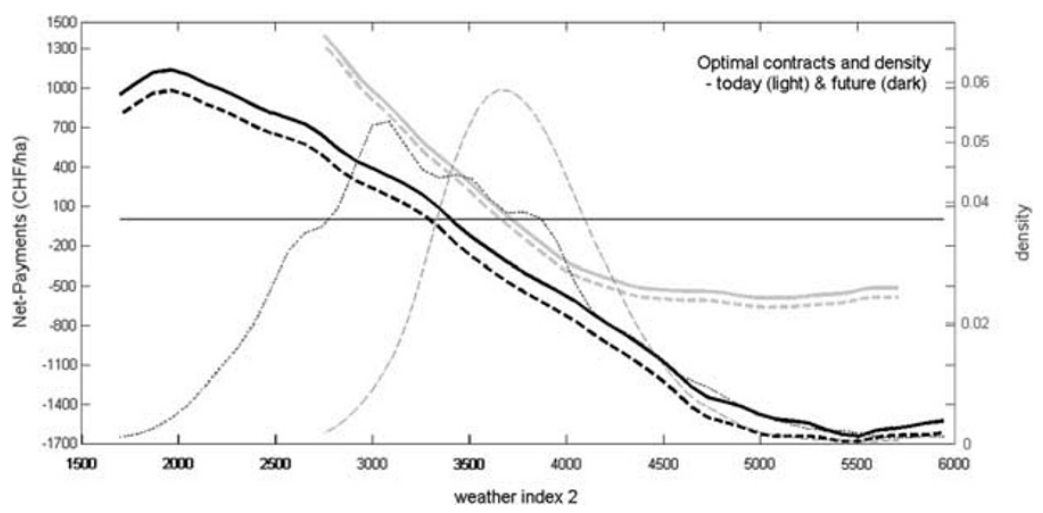

Figure 4. Optimal (solid line) and profit-maximising (dashed line) insurance contracts for Index 2 with density, for the baseline (light) and future scenario (dark).

The optimal future contract accounts for these new weather conditions in two ways: (i) the payoff function covers these additional weather extremes, and (ii) the shape of the payoff function changes (for each realisations of the index). In particular, we find that the future optimal payoff function, $p_{f}$, is defined over a wider range of index realisations that covers these additional drought-like conditions. Under today's climatic conditions, $p_{t}$ for Index 2 is defined for values of $z$ between $2,749 \mathrm{CHF} / \mathrm{ha}$ and $5,707 \mathrm{CHF} / \mathrm{ha}$. With climate change, the smallest value of $z$ is $1,791 \mathrm{CHF} / \mathrm{ha}$ and the maximum is $5,941 \mathrm{CHF} / \mathrm{ha}$.

While the range of weather events covered increases, the magnitude of each netpayoff decreases with climate change for the entire range of the weather index. The maximum net-payment decreases from 1,399 CHF for today's contract to $1.133 \mathrm{CHF}$ for an adjusted optimal contract (given Index 2). Note that the probability of having to pay the full premium is in both climate scenarios very small, as can be seen from Figure 4, which shows today's optimal contract and the future optimal contract together with the densities of the respective weather indices. ${ }^{47}$ At the same time, the premiums for optimal adjusted contracts more than double (depending on the index). For instance, in the baseline scenario an optimal insurance contract costs 593.0 CHF, and with climate change, an adjusted optimal contract costs 1,645 CHF (based on Index 2).

We also find that while the recovery point of adjusted future contracts shifts to the left, the recovery probability increases. ${ }^{48}$ Given today's climate, the insured recovers the premium almost every second year (49.5-51.5 per cent), and with climate change the recovery probability increases to $51.9-57.7$ per cent (depending on the index). Table 5 provides an overview of the premiums, maximum payments, and the recovery probabilities for the baseline and the future scenario. For today's climate, high net-payments

\footnotetext{
${ }^{47}$ The optimal and profit-maximising insurance contracts for Indices 1, 3, and 4 follow the same pattern, see Kapphan et al. (2011).

${ }^{48}$ The recovery probability is the probability of realising index values equal or smaller than the recovery point.
} 
Table 5 Contract parameters of optimal, adjusted contracts

\begin{tabular}{|c|c|c|c|c|c|c|c|}
\hline Net-payment & Premium & $\begin{array}{l}\text { Max. } \\
\text { payout }\end{array}$ & $\begin{array}{c}\text { Recovery } \\
\text { probability }(\%)\end{array}$ & $\begin{array}{l}500 \text { to } \max . \\
\text { payout }(\%)\end{array}$ & $\begin{array}{c}0 \text { to } \\
500(\%)\end{array}$ & $\begin{array}{l}-500 \text { to } \\
0(\%)\end{array}$ & $\begin{array}{c}\text { Premium } \\
\text { to }-500(\%)\end{array}$ \\
\hline \multicolumn{8}{|l|}{ Index 1} \\
\hline Today & 640.3 & 971.8 & 51.2 & 11.5 & 39.2 & 42.1 & 7.2 \\
\hline Future & 1,634 & 776.2 & 51.9 & 15.6 & 36.6 & 37.4 & 10.7 \\
\hline \multicolumn{8}{|l|}{ Index 2} \\
\hline Today & 593.0 & 1,399 & 49.6 & 12.8 & 36.7 & 40.3 & 10.2 \\
\hline Future & 1,645 & 1,133 & 57.7 & 24.2 & 33.6 & 23.1 & 19.1 \\
\hline \multicolumn{8}{|l|}{ Index 3} \\
\hline Today & 624.7 & 1,579 & 51.5 & 13.4 & 38.1 & 45.9 & 2.6 \\
\hline Future & 1,640 & 1,149 & 55.6 & 26.6 & 29.1 & 23.8 & 20.5 \\
\hline \multicolumn{8}{|l|}{ Index 4} \\
\hline Today & 602.9 & 1,650 & 49.5 & 16.7 & 32.9 & 41.8 & 8.6 \\
\hline Future & 1,675 & 1,141 & 55.2 & 27.2 & 28.1 & 23.6 & 21.1 \\
\hline
\end{tabular}

Note: Payments and maximum payout are measured in $\mathrm{CHF} / \mathrm{ha}$.

$\left(p_{t} \geqslant 500 \mathrm{CHF}\right)$ only occur with low probabilities $(11.5-16.7$ per cent), and the likelihood of weather events that cause net-payments less than $-500 \mathrm{CHF}\left(p_{t} \leqslant-500\right)$ is between 2.6 per cent and 10.2 per cent (depending on the index). With climate change, the probability of the contract paying more than $500 \mathrm{CHF}$ almost doubles (for Indices 2 and 3), and ranges from 15.6 per cent to 27.2 per cent (depending on the index). This explains why we observe an increase in the premiums and in their likelihoods. For all indices, the probability of moderate net-payments between $500 \mathrm{CHF}$ and $0 \mathrm{CHF}$ decreases, together with the probability of having to pay between 0 and $-500 \mathrm{CHF}$. Figure 4 shows in addition the adjusted, profit-maximising insurance contracts. While the profit-maximising contracts, $\tilde{p_{t}}$ and $\tilde{p_{f}}$, possess the same shape as their actuarially fair counterparts, $p_{t}$ and $p_{f}$, they pay out less at each realisation of $z$. The difference in net-payments $\left(\tilde{p_{c}}-p_{c}\right)$ is captured by the insurer. With climate change, the difference in net-payments increases, and hence profits increase (see section "Expected profits from profit-maximising adjusted contracts").

Future optimal contracts thus offer an increased protection against extreme events (i.e. higher probability of high net-payments with $p_{f} \geqslant 500$ ), while they provide slightly reduced moderate payments (between 500 and $-500 \mathrm{CHF}$ ) for moderate deviations from the mean of the weather index. The increased coverage against the more frequent occurrence of extreme events is partially financed by decreasing net-payments over the entire range of all weather realisations and by substantially increasing the premiums in those rare years with excellent weather conditions.

\section{Hedging effectiveness of optimal adjusted contracts}

We evaluate the risk reduction from hedging weather risk by deriving $\delta_{c}$ for all climatic phases as described in the "Theoretical approach" section, for a moderate risk aversion level $(\sigma=2)$. Buying optimal weather insurance today is equivalent to 
Table $6 \delta$ (in per cent) for optimal adjusted contracts over time

\begin{tabular}{|c|c|c|c|c|}
\hline & Index 1 & Index 2 & Index 3 & Index 4 \\
\hline $\begin{array}{l}\text { Today } \\
(S t d)\end{array}$ & $\begin{array}{c}1.37 \\
(0.15)\end{array}$ & $\begin{array}{c}1.83 \\
(0.18)\end{array}$ & $\begin{array}{c}1.82 \\
(0.23)\end{array}$ & $\begin{array}{c}2.09 \\
(0.24)\end{array}$ \\
\hline $\begin{array}{l}\text { Moderate } \\
(S t d)\end{array}$ & $\begin{array}{c}2.23 \\
(0.19)\end{array}$ & $\begin{array}{c}3.04 \\
(0.18)\end{array}$ & $\begin{array}{c}2.98 \\
(0.18)\end{array}$ & $\begin{array}{c}3.31 \\
(0.16)\end{array}$ \\
\hline $\begin{array}{l}\text { Medium } \\
(S t d)\end{array}$ & $\begin{array}{c}2.78 \\
(0.00)\end{array}$ & $\begin{array}{c}3.90 \\
(0.12)\end{array}$ & $\begin{array}{c}3.86 \\
(0.11)\end{array}$ & $\begin{array}{c}4.20 \\
(0.15)\end{array}$ \\
\hline $\begin{array}{l}\text { Strong } \\
(S t d)\end{array}$ & $\begin{array}{c}3.01 \\
(0.17)\end{array}$ & $\begin{array}{c}4.57 \\
(0.10)\end{array}$ & $\begin{array}{c}4.54 \\
(0.11)\end{array}$ & $\begin{array}{c}4.92 \\
(0.11)\end{array}$ \\
\hline $\begin{array}{l}\text { Future } \\
(S t d)\end{array}$ & $\begin{array}{c}3.00 \\
(0.20)\end{array}$ & $\begin{array}{c}4.99 \\
(0.25)\end{array}$ & $\begin{array}{c}4.98 \\
(0.28)\end{array}$ & $\begin{array}{c}5.42 \\
(0.26)\end{array}$ \\
\hline
\end{tabular}

increasing the income of the insured in all states of the world by 1.37-2.09 per cent (depending on the index). We observe that with climate change, $\delta_{c}$ from hedging with adjusted optimal contracts increases continually over time and more than doubles up to the year 2050. When buying an adjusted optimal contract in the future, the insured's income in the situation without insurance would need to be increased by 3.00-5.42 per cent (depending on the index) to make the insured as well off (in expected utility terms) as in the situation with insurance.

Thus, with climate change, the insured attributes a higher value of hedging weather risk with an optimal adjusted contract. The standard deviation for these estimates does not increase significantly over time. We have restricted the analysis to a moderate level of risk aversion. The hedging benefits for a more risk-averse individual $(\sigma>2)$ under both today's and future climate conditions are even more substantial. ${ }^{49}$ Table 6 shows the estimates of $\delta_{c}$ with the corresponding standard deviation for all indices and climatic scenarios, and in Figure 5, we show boxplots of $\delta_{c}$ over time for all indices.

We also compare the income distribution without insurance to the situation where the farmer uses an optimal adjusted contract, $p_{c}$, and, respectively, a profit-maximising contract, $\tilde{p}_{c}$, to hedge his weather risk in today's and future climatic conditions. Given today's weather conditions, the mean income without insurance is $3,696 \mathrm{CHF} / \mathrm{ha}$ with a standard deviation of $186.3 \mathrm{CHF} /$ ha. The optimal insurance contract, $p_{t}$, preserves the mean income but greatly reduces the standard deviation to $106.6-139.9 \mathrm{CHF} / \mathrm{ha}$ (depending on the index). The income distribution with a profit-maximising contract, $\tilde{p}_{t}$, possesses the same standard deviations as with $p_{t}$, but the average income is reduced by $49-75 \mathrm{CHF} /$ ha (depending on the index). With climate change, the mean income without insurance decreases by more than 10 per cent (to $3,294 \mathrm{CHF} / \mathrm{ha}$ ), while

\footnotetext{
${ }^{49}$ Kapphan (2011) shows for today's climatic conditions using the same weather indices and optimal contracts that with a coefficient of relative risk aversion of $\sigma \in[5,7], \delta_{t}$ is between 4.2 per cent and 10.7 per cent.
} 

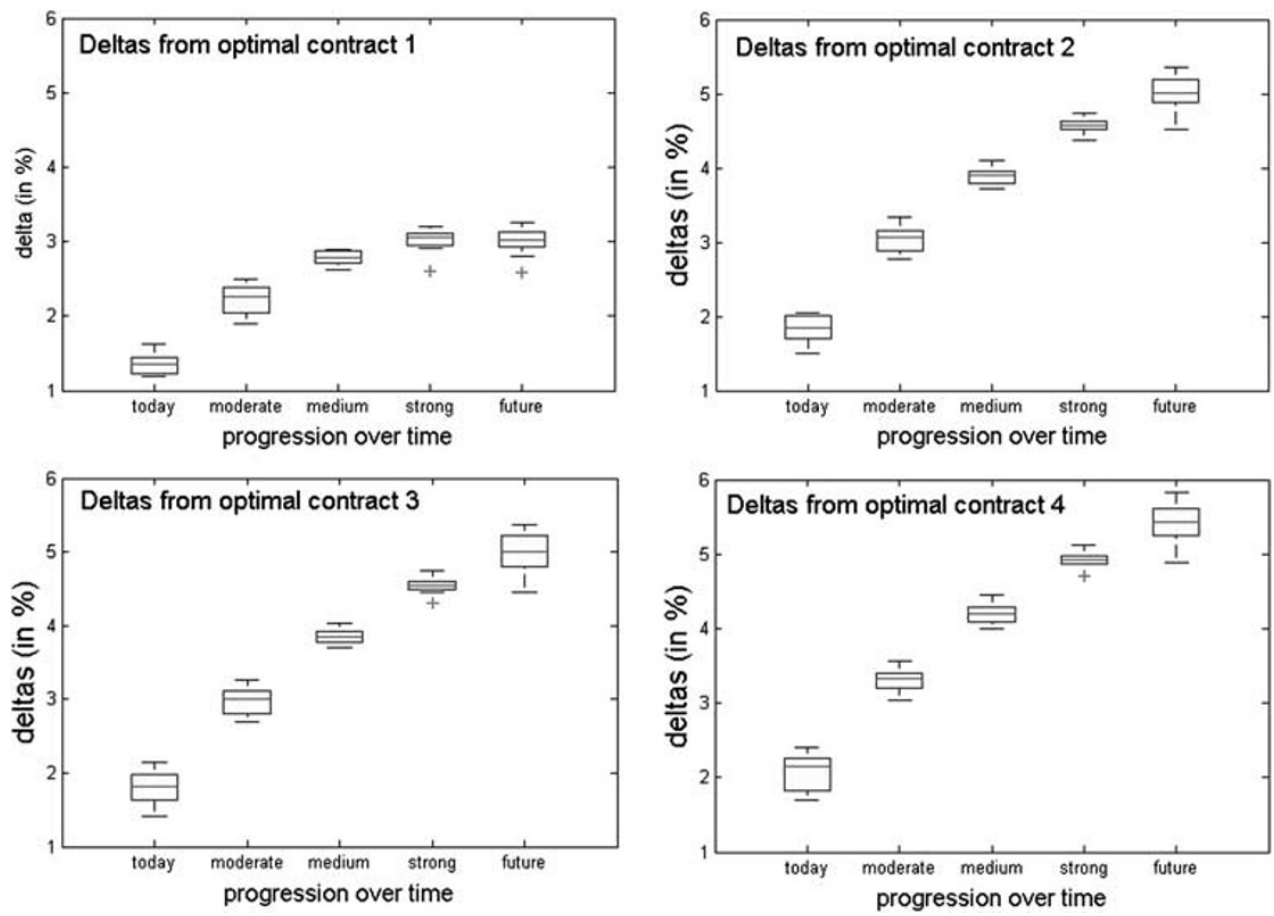

Figure 5. Evolution of $\delta$ (in per cent) over time for all optimal adjusted contracts.

the standard deviation increases by 49.9 per cent (to $279.4 \mathrm{CHF} / \mathrm{ha}$ ). An adjusted optimal insurance contract, $p_{f}$, such as the one based on Index 4, can reduce the future standard deviation by factor 2 (to $130,6 \mathrm{CHF} / \mathrm{ha}$ ). The profit-maximising adjusted contract, $\tilde{p}_{f}$, achieves the same risk reduction but lowers the average future income (by $88-163 \mathrm{CHF} / \mathrm{ha}$, depending on the index) compared to the future unhedged situation. Figure 6 shows the income distributions with insurance, for both the optimal and profit-maximising contract, and for the scenario without hedging for both climate scenarios.

When hedging weather risk today and in the future with climate change, the insured faces less risk of realising very low incomes and lower probabilities of realising very high incomes, that is the insurance contracts compresses the income distribution. An optimal weather insurance contract thus redistributes incomes over time from good harvest years to bad years.

In conclusion, both types of adjusted insurance contracts reduce the risk of realising low incomes. When comparing the hedging effectiveness of our contracts over time, we find that the benefits from using weather insurance increases significantly with climate change, which is due to the fact that with climate change weather exerts a stronger influence on crop yields. That is, with climate change, the preconditions for hedging yield risk with an index-based weather insurance product improves. We have shown that these findings are robust across indices and independent from the risk measure used. 


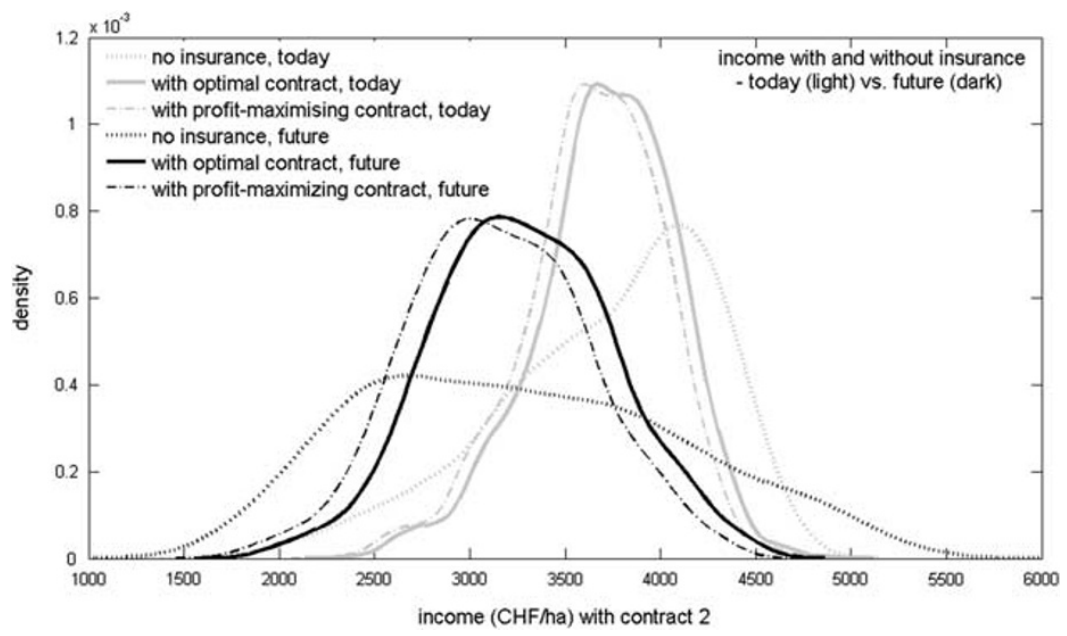

Figure 6. Income distributions with optimal (solid line) and profit-maximising (dashed line) insurance based on Index 2 and without insurance (pointed line) for the baseline (light) and the future scenario (dark).

When hedging with a profit-maximising contract, the insured gets the same risk reduction (as measured by the standard deviation of the income distribution) as with a zero-profit contract, but at the cost of a reduced (average) income. ${ }^{50}$ By evaluating the hedging benefits of a profit-maximising contract, we have considered the extreme case where the insurer captures the entire gain from hedging, so that the insured is (in expected utility terms) indifferent to the unhedged situation. In practice, these gains can be shared between the insurer and the insured. For all risk measures, we observe that there is a variation of hedging benefits across contracts. In general, the better the goodness-of-fit of the underlying index with crop yields, the better the risk reduction.

\section{Expected profits from profit-maximising adjusted contracts}

We derive the expected profits, $\Pi_{c}$, that an insurer can expect to earn from offering a profit-maximising insurance contract by solving profit for all climate scenarios given $\tilde{p_{c}}$ and $g_{c}(z){ }^{51}$ Table 7 shows the expected profits for all indices over time together with the estimated standard deviation, for $\sigma=2$. For today's climatic conditions, the insurer can expect to earn between 41.6 to $67.2 \mathrm{CHF} /$ ha of insured maize. We find that with climate change, expected profits increase gradually over time and reach substantial values. For instance, expected profits for Index 1 double, and

${ }^{50}$ For a given level of risk aversion, it can be shown that a range of loading factors exist at which the insured prefers a loaded contract (compared to remaining unhedged) despite the fact that the contract is not actuarially fair. The range of loading factors for which this is true can be determined with the help of the profit-maximising contract. From the profit-maximising contract, the maximum loading factor at which the insured is indifferent between hedging his weather risk and not insuring can be determined. The statement is then true for any loading factor smaller than the maximum loading factor.

${ }^{51}$ Note that the expected profits from an optimal adjusted insurance contract are zero by construction. 
Table 7 Profits (П) from profit-maximising adjusted contracts over time

\begin{tabular}{|c|c|c|c|c|}
\hline & Index 1 & Index 2 & Index 3 & Index 4 \\
\hline $\begin{array}{l}\text { Today } \\
(S t d)\end{array}$ & $\begin{array}{l}41.61 \\
(4.24)\end{array}$ & $\begin{array}{l}61.29 \\
(5.84)\end{array}$ & $\begin{array}{l}58.78 \\
(4.96)\end{array}$ & $\begin{array}{l}67.29 \\
(6.42)\end{array}$ \\
\hline $\begin{array}{l}\text { Moderate } \\
(S t d)\end{array}$ & $\begin{array}{l}74.80 \\
(6.10)\end{array}$ & $\begin{array}{r}103.08 \\
(5.99)\end{array}$ & $\begin{array}{r}100.94 \\
(6.01)\end{array}$ & $\begin{array}{r}112.56 \\
(5.30)\end{array}$ \\
\hline $\begin{array}{l}\text { Medium } \\
(S t d)\end{array}$ & $\begin{array}{l}89.51 \\
(2.94)\end{array}$ & $\begin{array}{r}126.93 \\
(3.85)\end{array}$ & $\begin{array}{r}125.62 \\
(3.58)\end{array}$ & $\begin{array}{r}137.32 \\
(4.64)\end{array}$ \\
\hline $\begin{array}{l}\text { Strong } \\
(S t d)\end{array}$ & $\begin{array}{c}92.20 \\
(5.32)\end{array}$ & $\begin{array}{r}142.2 \\
(3.23)\end{array}$ & $\begin{array}{r}141.48 \\
(3.51)\end{array}$ & $\begin{array}{r}153.84 \\
(3.43)\end{array}$ \\
\hline $\begin{array}{l}\text { Future } \\
(S t d)\end{array}$ & $\begin{array}{c}88.28 \\
(5.92)\end{array}$ & $\begin{array}{r}149.56 \\
(7.42)\end{array}$ & $\begin{array}{r}149.20 \\
(8.30)\end{array}$ & $\begin{array}{r}163.30 \\
(8.00)\end{array}$ \\
\hline
\end{tabular}

Note: Profits are measured in $\mathrm{CHF} / \mathrm{ha}$.
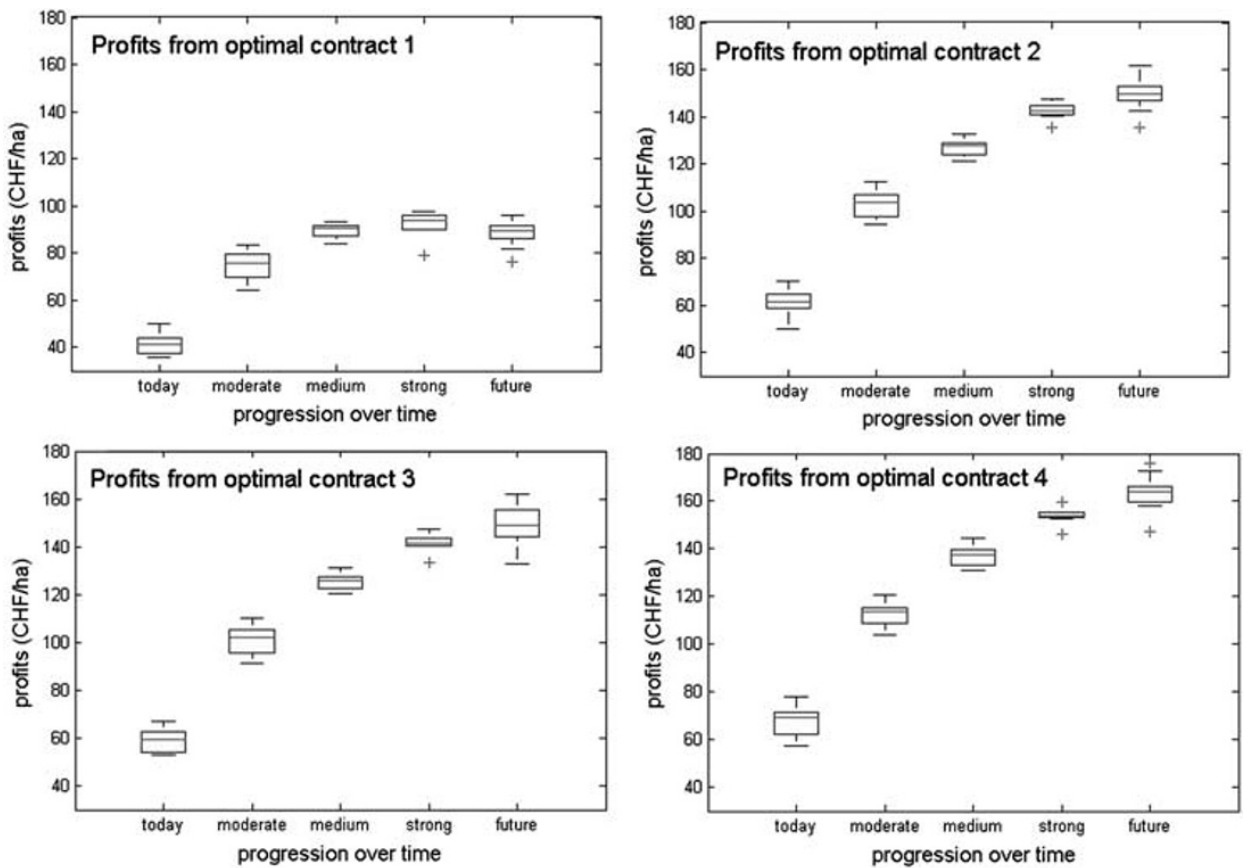

Figure 7. Evolution of profits (in $\mathrm{CHF} / \mathrm{ha}$ ) over time for all profit-maximising adjusted contracts.

they increase by 240 per cent for the other three indices by the year 2050. In Figure 7 , we present boxplots of expected profits over time for all indices.

We observe that the variation in expected profits across indices as well as the variation of $\delta_{c}$ across indices (as seen in section "Hedging effectiveness of optimal 
adjusted contracts") is related to the goodness-of-fit of the underlying weather indices with maize yields. The higher the correlation of the weather index with yields, the better the hedging effectiveness (as measured by $\delta$ ) and the higher are expected profits (as measured by $\Pi$ ).

\section{Results: non-adjusted weather insurance contracts}

\section{Comparison of adjusted and non-adjusted contracts}

We now examine the risk reduction from hedging future weather risk with non-adjusted insurance contracts. For that purpose, we first analyse the payout probabilities of non-adjusted contracts, which were initially priced and designed for today's weather conditions but are used under future climatic conditions. Next, the payout-probabilities of non-adjusted contracts are compared to the payout characteristics of adjusted contracts in future climatic conditions, see Table 8 .

We find that the non-adjusted contracts based on Indices 1 and 4 have higher recovery probabilities than the corresponding adjusted contracts. For instance, the insured recovers the premium of an adjusted contract (based on Index 4) with a probability of 55.2 per cent, while the premium is recovered with a probability of 84.6 per cent with the non-adjusted contract. The increase in the recovery probability of non-adjusted contracts 1 and 4 is a result of an increase in the occurrence of weather events that trigger very high net-payments. For Index 4, the probability of net-payments above $500 \mathrm{CHF}$ increases from 27.2 per cent (given an adjusted contract) to 55.2 per cent with the non-adjusted contract.

For Indices 2 and 3, we find that the likelihood of fully recovering the premium decreases. The adjusted contract based on Index 2 triggers very high net-payments $\left(p_{f}(z)>500 \mathrm{CHF}\right)$ with 24.2 per cent, while the non-adjusted contract delivers high net-payments only with a probability of 10.0 per cent. This implies that the nonadjusted contracts based on Indices 2 and 3 do not provide sufficiently high netpayments when needed.

The non-adjusted contracts based on Indices 1 and 4 provide, however, very high netpayments even in situations where smaller payments would have been sufficient to cover the losses. For Indices 1 and 4, the non-adjusted contracts trigger net-payments of less than $-500 \mathrm{CHF}\left(p_{f}(z) \leqslant-500\right)$ less often than the corresponding adjusted contracts. For instance, the probability of net-payments that are less than $-500 \mathrm{CHF}$ is 2.2 per cent with the non-adjusted contract, compared to 21.1 per cent with the adjusted contract. With future weather conditions, an actuarial fair contract implies that the insured can expect to pay the full premium approximately every $5^{\text {th }}$ year (given that excellent weather conditions have a return period of 21.1 per cent). With non-adjusted contracts (based on Index 4), this event happens only every 50 years. This already suggests that the non-adjusted contract will no longer be profitable to the insurer.

Comparing the payout probabilities of non-adjusted contracts with those from adjusted contracts provides a first impression of the weather events that are being hedged by non-adjusted contracts. Non-adjusted contracts 1 and 4 provide positive net-payments with a higher probability, while the probabilities of negative net-payments decrease (compared to the corresponding adjusted contract). For 


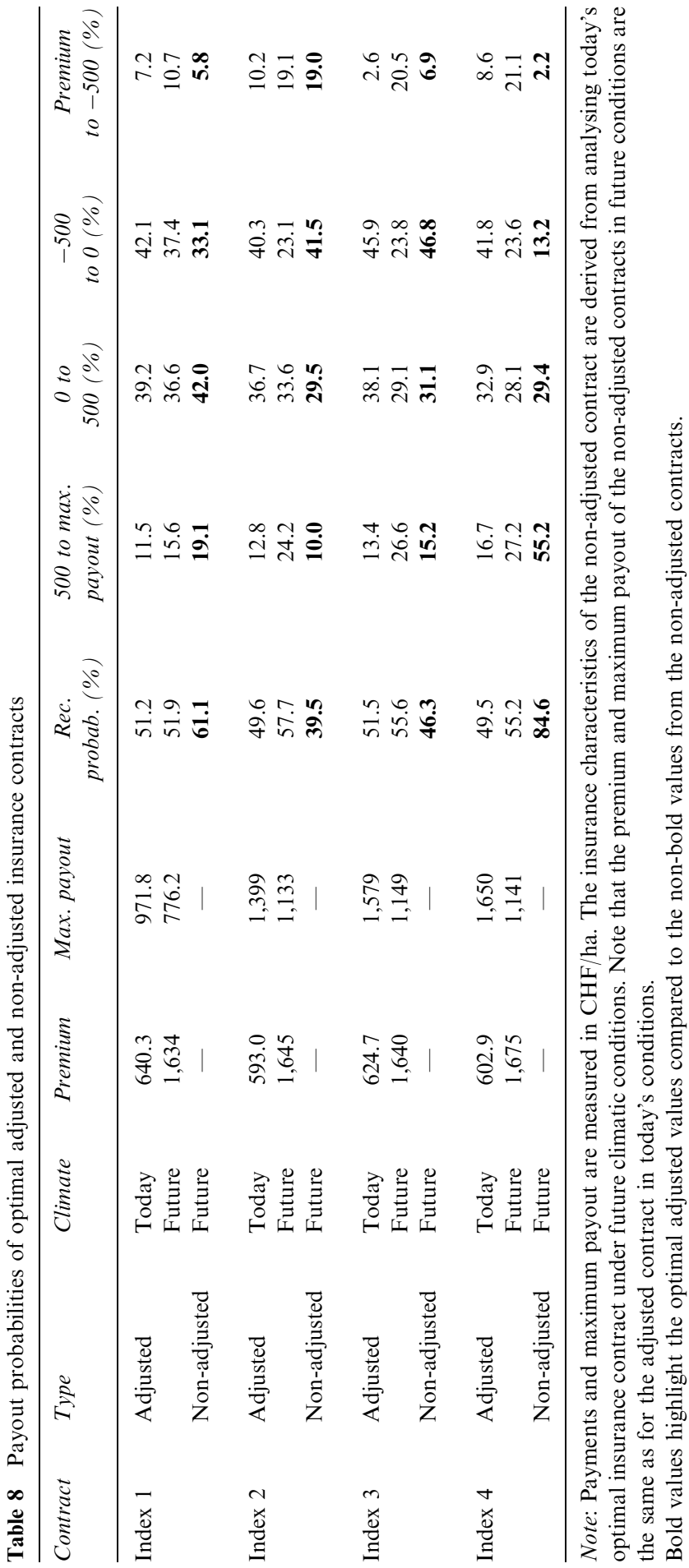


contracts 2 and 3, it is less clear if the insured is better or worse off with the nonadjusted contracts. For that purpose, we turn to the evaluation of the hedging effectiveness of non-adjusted contracts. Risk measures are better suited to discriminate between different insurance contracts.

\section{Hedging effectiveness and expected profits of non-adjusted contracts}

To determine the hedging effectiveness of non-adjusted contracts, we derive $\delta_{c}$ from hedging with the optimal and profit-maximising non-adjusted contracts, and compare it with the hedging effectiveness of the adjusted contract. For a more realistic comparison, we take into account that insurers are updating the design and pricing of their insurance products over long time periods, such as the one considered here, that is between 1990 and 2050. In particular, we assume that insurers adapt their weather insurance products at the end of each climate scenario, that is they use the new weather and yield data that is becoming available to update their contracts for the coming scenario. For that purpose, we use the interim scenarios and simulate first the adjusted insurance contracts $\left(p_{c}\right.$ and $\left.\tilde{p}_{c}\right)$ for all scenarios $c \in\{t, 75 / 25,50 / 50,25 /$ $75, f\}$. We derive the income distributions in each climate scenario $c$ from hedging with the non-adjusted (optimal and profit-maximising) contracts from the previous period $c-1$. We then determine $\delta_{c}$ for hedging weather risk in $c$ with non-adjusted optimal insurance products, that is $\delta_{c}\left(p_{c-1}(z)\right)$, and for hedging with a non-adjusted profit-maximising contract, that is $\delta_{c}\left(\tilde{p}_{c-1}(z)\right) .{ }^{52}$ Table 9 summarises the results, and Figure 8 shows the evolution of $\delta_{c}$ for adjusted and non-adjusted contracts over time for all indices. We find that $\delta_{c}\left(p_{c-1}(z)\right)$ can be bigger or smaller than $\delta_{c}\left(p_{c}(z)\right)$. In contrast to hedging with adjusted contracts, we observe that $\delta_{c}\left(p_{c-1}(z)\right)$ takes on negative values, that is the expected utility of the insured is reduced through insurance. As a result, such non-adjusted contracts would not be purchased.

Furthermore, we determine the expected profits for insurers from offering nonadjusted weather insurance contracts. For that purpose, we derive the expected profits, $\Pi_{c}$, in each climate scenario from offering the non-adjusted, optimal $\left(p_{c-1}(z)\right)$ and non-adjusted, profit-maximising contract $\left(\tilde{p}_{c-1}(z)\right)$. We then compare $\Pi_{c}\left(p_{c-1}(z)\right)$ and, respectively, $\Pi_{c}\left(\tilde{p}_{c-1}(z)\right)$ with the expected profits from the adjusted profit-maximising contract, $\Pi_{c}\left(\tilde{p}_{c}(z)\right)$. Table 10 reports the profits from non-adjusted contracts together with the profits from adjusted contracts, and Figure 9 shows the evolution of profits from adjusted and non-adjusted contracts over time for all indices. We find that some non-adjusted contracts create losses for the insurer and as a result would not be offered. By evaluating the risk reduction (for the insured) from non-adjusted contracts and simultaneously assessing the profitability (for the insurer), we capture over time the effect of using backward-looking data to design and price weather insurance products in light of climate change.

In the moderate scenario, we observe that non-adjusted optimal and profit-maximising contracts, based on Indices 1, 2, and 3, generate positive profits. These profits, $\Pi_{75 / 25}\left(p_{t}(z)\right)=145.8-310.1 \mathrm{CHF} /$ ha and, respectively,

\footnotetext{
${ }^{52}$ Note that $\delta_{c}\left(\tilde{p}_{c-1}\right)$ is in contrast to $\delta_{c}\left(\tilde{p_{c}}\right)$ not necessarily equal to zero.
} 
Table $9 \delta($ in $\%)$ for adjusted and non-adjusted insurance contracts

\begin{tabular}{|c|c|c|c|c|}
\hline & Index 1 & Index 2 & Index 3 & Index 4 \\
\hline \multicolumn{5}{|l|}{ Today } \\
\hline \multicolumn{5}{|l|}{ Adjusted } \\
\hline Optimal & 1.37 & 1.83 & 1.82 & 2.09 \\
\hline$(S t d)$ & $(0.15)$ & $(0.18)$ & $(0.23)$ & $(0.24)$ \\
\hline \multicolumn{5}{|l|}{ Moderate } \\
\hline \multicolumn{5}{|l|}{ Adjusted } \\
\hline Optimal & 2.23 & 3.04 & 2.98 & 3.31 \\
\hline$(S t d)$ & $(0.19)$ & $(0.18)$ & $(0.18)$ & $(0.16)$ \\
\hline \multicolumn{5}{|c|}{ Non-adjusted } \\
\hline Optimal & -2.42 & -6.98 & -5.34 & 12.93 \\
\hline$(S t d)$ & 1.10 & 1.37 & 1.38 & 2.67 \\
\hline Profit & -3.82 & -8.95 & -7.23 & 10.81 \\
\hline$(S t d)$ & 1.10 & 1.38 & 1.38 & 2.67 \\
\hline \multicolumn{5}{|l|}{ Medium } \\
\hline \multicolumn{5}{|l|}{ Adjusted } \\
\hline Optimal & 2.78 & 3.90 & 3.86 & 4.20 \\
\hline$(S t d)$ & 0.00 & 0.12 & 0.11 & 0.15 \\
\hline \multicolumn{5}{|c|}{ Non-adjusted } \\
\hline Optimal & 9.28 & 6.23 & 6.56 & 5.88 \\
\hline$(S t d)$ & 1.60 & 1.39 & 1.67 & 2.04 \\
\hline Profit & 7.23 & 3.40 & 3.76 & 2.76 \\
\hline$(S t d)$ & 1.60 & 1.38 & 1.67 & 2.04 \\
\hline \multicolumn{5}{|l|}{ Strong } \\
\hline \multicolumn{5}{|l|}{ Adjusted } \\
\hline Optimal & 3.01 & 4.57 & 4.54 & 4.92 \\
\hline$(S t d)$ & 0.17 & 0.10 & 0.11 & 0.11 \\
\hline \multicolumn{5}{|c|}{ Non-adjusted } \\
\hline Optimal & 6.31 & 8.87 & 8.74 & 9.39 \\
\hline$(S t d)$ & 1.16 & 0.53 & 1.19 & 1.60 \\
\hline Profit & 3.37 & 6.07 & 4.87 & 5.21 \\
\hline$(S t d)$ & 1.17 & 0.52 & 1.19 & 1.58 \\
\hline \multicolumn{5}{|l|}{ Future } \\
\hline \multicolumn{5}{|l|}{ Adjusted } \\
\hline Optimal & 3.00 & 4.99 & 4.98 & 5.42 \\
\hline$(S t d)$ & 0.20 & 0.25 & 0.28 & 0.26 \\
\hline \multicolumn{5}{|c|}{ Non-adjusted } \\
\hline Optimal & 5.36 & 8.12 & 8.14 & 10.04 \\
\hline$(S t d)$ & 1.82 & 0.97 & 3.04 & 1.93 \\
\hline Profit & 2.24 & 3.39 & 3.43 & 4.92 \\
\hline$(S t d)$ & 1.82 & 0.95 & 3.02 & 1.92 \\
\hline
\end{tabular}

Note: $\delta$ is the percentage increase of all income realisations without insurance compared to the situation with insurance. Deltas $\left(\delta_{c}(z)\right)$ from non-adjusted contracts in a given climate scenario $(c)$ are derived by applying the optimal $\left(p_{c-1}(z)\right)$ or the profit-maximising $\left(\tilde{p}_{c-1}(z)\right)$ insurance contract from the previous climate scenario $(c-1)$ to the current climate scenario. Deltas from adjusted contracts are derived by applying the optimal insurance contract $\left(p_{c}(z)\right)$ to the conditions for which it is derived, namely to $c$.

Bold values highlight the optimal adjusted values compared to the non-bold values from the non-adjusted contracts. 

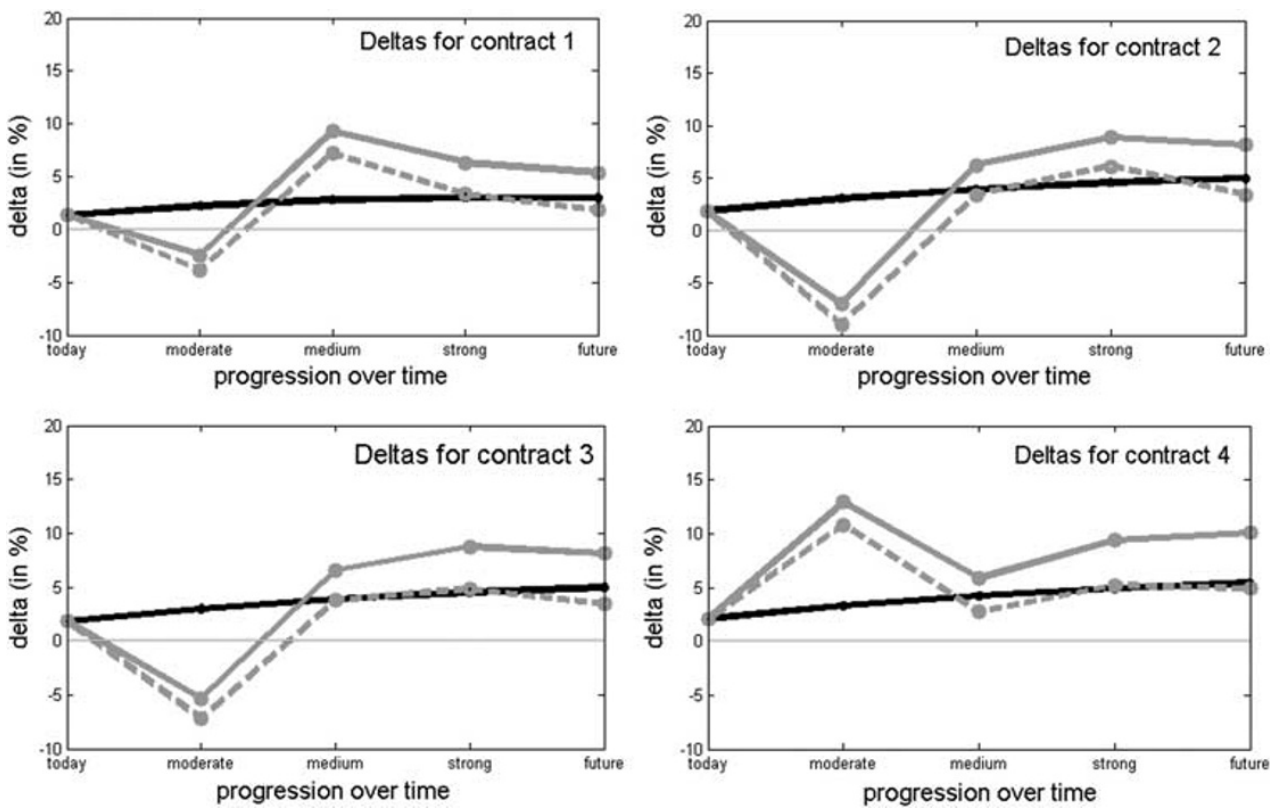

Figure 8. Delta (in per cent ) for adjusted (dark) and non-adjusted optimal (light, solid line) and nonadjusted profit-maximising contracts (light, dashed line) are shown over time for all indices. The nonadjusted $\delta_{c}$ from hedging with an optimal contract $\delta_{c}\left(p_{c-1}(z)\right)$ is derived by determining the risk reduction in climate scenario $c$ from hedging with an optimal contract $\left(p_{c-1}(z)\right)$ from the previous period $c-1$. Hedging in $c$ with a non-adjusted profit-maximising contract from the previous period yields $\delta_{c}\left(\tilde{p}_{c-1}(z)\right)$.

$\Pi_{i}\left(\tilde{p_{t}}(z)\right)=192.9-375.9 \mathrm{CHF} / \mathrm{ha}$, are substantially higher than the profits from the adjusted profit-maximising contracts.

$\Pi_{75 / 25}\left(\tilde{p}_{75 / 25}(z)\right)$ ranges between $=74.8$ to $112.5 \mathrm{CHF} /$ ha depending on the index. In contrast, the non-adjusted contracts based on Index 4 generate negative profits ( -260.6 to $-332.8 \mathrm{CHF} / \mathrm{ha}$, depending on the type of contract) for the insurer. At the same time, $\delta_{75 / 25}\left(p_{t}(z)\right)$ is between -2.42 per cent and -6.98 per cent, for Indices 1 , 2 , and 3 . The non-adjusted profit-maximising contract makes the insured in the moderate scenario even worse off, that is $\delta_{75 / 25}\left(\tilde{p}_{t}(z)\right)$ is between -3.82 per cent and -8.95 per cent for contracts based on Indices 1, 2, and 3. Therefore, contracts 1, 2 and 3 would not be bought by the insured.

Hedging with an adjusted contract, $\delta_{75 / 25}\left(p_{75 / 25}(z)\right)$, in contrast generates 'positive hedging benefits of 2.23-3.31 per cent (depending on the index). With the non-adjusted contracts based on Index 4, which generate a four times higher $\delta_{c}$ than the corresponding adjusted contract, the insured's crop losses would be overcompensated. Since this contract generates losses of -260.6 to $-332.8 \mathrm{CHF} /$ ha (depending on the type of contract), it will, however, not be offered by the insurer.

The situation changes in the medium scenario. For all indices, $\delta_{50 / 50}\left(p_{75 / 25}(z)\right)$ takes on values that are higher than $\delta_{50 / 50}\left(p_{50 / 50}(z)\right)$ from the adjusted contracts. 
Table 10 Profits (in $\mathrm{CHF} /$ ha) for adjusted and non-adjusted contracts

\begin{tabular}{|c|c|c|c|c|}
\hline & Index 1 & Index 2 & Index 3 & Index 4 \\
\hline \multicolumn{5}{|l|}{ Today } \\
\hline \multicolumn{5}{|l|}{ Adjusted } \\
\hline Optimal & 41.61 & 61.29 & 58.78 & 67.29 \\
\hline$(S t d)$ & 4.24 & 5.84 & 4.96 & 6. \\
\hline \multicolumn{5}{|l|}{ Moderate } \\
\hline \multicolumn{5}{|l|}{ Adjusted } \\
\hline Optimal & 74.80 & 103.08 & 100.94 & 112.56 \\
\hline$(S t d)$ & 6.1 & 5.9 & 6.0 & 5.3 \\
\hline \multicolumn{5}{|c|}{ Non-adjusted } \\
\hline Optimal & 145.8 & 310.1 & 257.7 & -332.8 \\
\hline$(S t d)$ & 36.4 & 39.6 & 42.6 & 93.4 \\
\hline Profit & 192.9 & 375.9 & 321.1 & -260.6 \\
\hline$(S t d)$ & 36.4 & 39.7 & 42.7 & 93.5 \\
\hline
\end{tabular}

Medium

Adjusted

Optimal

89.51

126.93

125.62

137.32

(Std)

Non-adjusted

$-79.1$

$-91.0$

$-57.1$

(Std)

51.6

44.3

65.0

Profit

$-146.4$

13.0

54.7

45.0

(Std)

51.6

44.3

0.15

65.0

Strong

Adjusted
Optimal

(Std)

Non-adjusted

Optimal

(Std)

Profit

(Std)

Future

\section{Adjusted \\ Optimal}

(Std)

Non-adjusted

Optimal

(Std)

Profit

(Std)
92.20

5.32

$-102.8$

36.83

$-12.6$

36.7

88.28

8.0

$-71.9$

53.1

19.8

53.0
142.2

3.23

$-135.4$

16.8

$-47.7$

17.1
141.48

3.51

$-132.5$

36.2

$-11.5$

36.2 $\mathbf{1 5 3 . 8 4}$

$-140.7$

48.8

$-9.6$

48.7

Note: Expected profits from adjusted and non-adjusted contracts (in $\mathrm{CHF} / \mathrm{ha}$ ) for all indices are shown over time, together with the standard deviation. Expected profits from non-adjusted contracts $\Pi_{c}\left(p_{c-1}\right)$, or $\Pi_{c}\left(\tilde{p}_{c-1}\right)$, in a given climate scenario $(c)$ are derived by calculating the net-payments from offering an optimal $\left(p_{c-1}(z)\right)$, or a profit-maximising $\left(\tilde{p_{c-1}}(z)\right)$ insurance contract from the previous climatic conditions $(c-1)$ in $c$. Crop: maize, location: SHA, model parameters: $n y=25, n z=50, b w(1)=100, b w(2)=300$, and $\sigma=2$.

Bold values highlight the optimal adjusted values compared to the non-bold values from the non-adjusted contracts. 

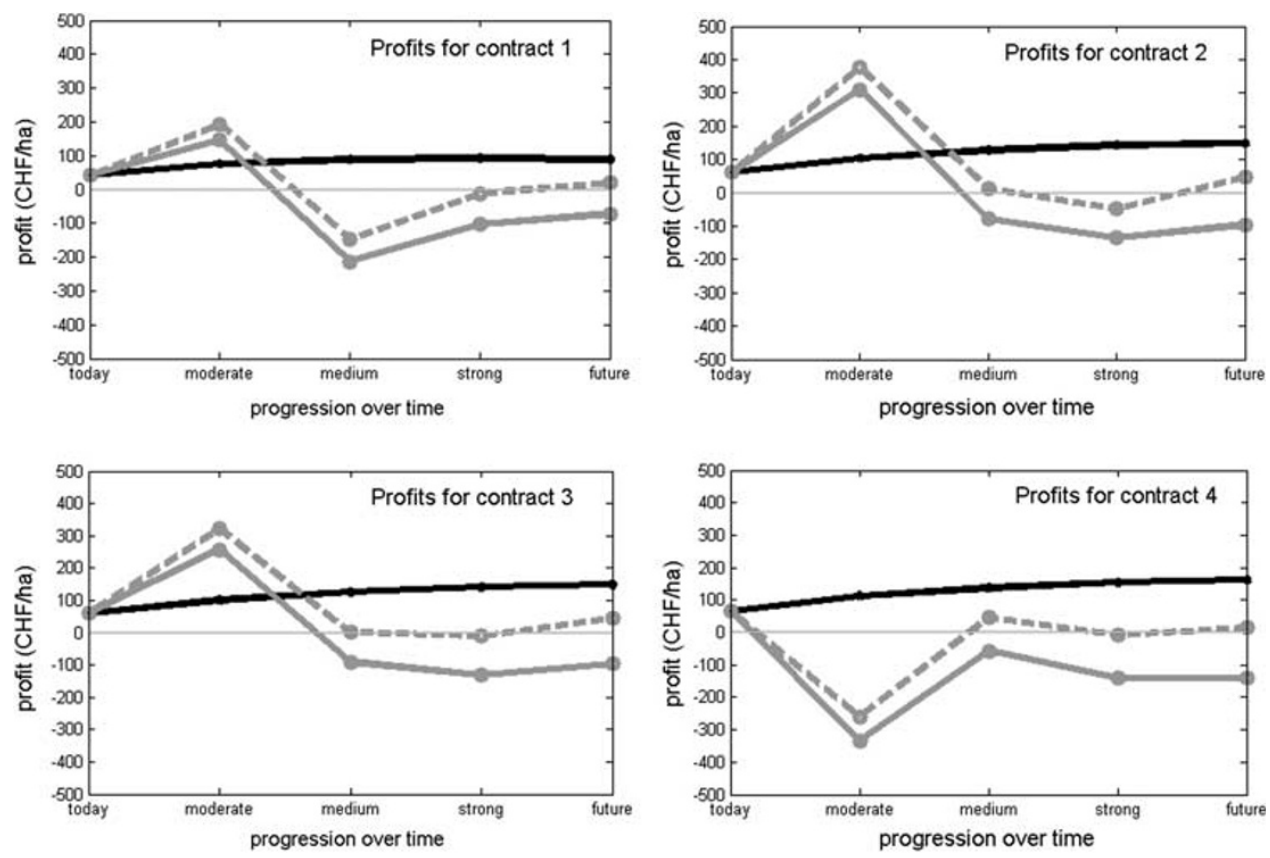

Figure 9. Profits (in $\mathrm{CHF} / \mathrm{ha}$ ) for adjusted (dark) and non-adjusted, optimal contracts (light, solid line) and non-adjusted, profit-maximising (light, dashed line) are shown over time for all indices. The $\Pi_{c}$ from hedging with an optimal non-adjusted contract $\Pi_{c}\left(p_{c-1}(z)\right)$ is derived by determining the expected profits in climate scenario $c$ from offering an optimal contract $\left(p_{c-1}(z)\right)$ from the previous period $c-1$. The $\Pi_{c}$ from offering a non-adjusted profit-maximising contract from the previous period yields $\Pi_{c}\left(\tilde{p}_{c-1}(z)\right)$.

The hedging effectiveness of the non-adjusted contract 3 ( 6.55 per cent) is almost twice as high as for the corresponding adjusted contracts (3.86 per cent), and the non-adjusted profit-maximising contract yields almost the same hedging benefits (3.76 per cent) as the adjusted contract ( 3.85 per cent). All non-adjusted optimal contrasts generate losses for the insurer.

While the non-adjusted optimal contracts generate losses for the insured, some nonadjusted profit-maximising contracts (based on Indices 2 and 4) generate positive profits. Expected profits for non-adjusted profit-maximising contracts, $\Pi_{f}\left(\tilde{p}_{75 / 25}(z)\right)$, range between 13.8 and $46.4 \mathrm{CHF} / \mathrm{ha}$ (depending on the index). In addition, we observe that the insured is (almost) indifferent between the non-adjusted profitmaximising contract and the adjusted optimal contract. ${ }^{53}$ Since $\delta_{50 / 50}\left(\tilde{p}_{75 / 25}(z)\right)$ and $\Pi_{50 / 50}\left(\tilde{p}_{75 / 25}(z)\right)$ are both positive, these non-adjusted contracts would be traded. We observe this pattern also in the future scenario.

In the future scenario, both non-adjusted contracts generate a higher $\delta_{c}$ than the adjusted contract. The non-adjusted optimal contract produces a higher $\delta_{c}$ than the

${ }^{53}$ When taking the standard deviation of $\delta_{c}$ into account, which is 1.6 per cent for the non-adjusted contract, compared to 0.11 per cent for the adjusted contract, it turns out that the hedging performance of the non-adjusted contract is more variable, making the non-adjusted contracts less attractive. 
non-adjusted profit-maximising contract. Given that expected profits for the nonadjusted optimal contracts, $\Pi_{f}\left(p_{25 / 75}(z)\right)$, are negative, these contracts will not be offered. The insurer could generate positive profits by offering the non-adjusted profit-maximising contracts, as they yield a positive risk reduction. In the future scenario, $\delta_{f}\left(\tilde{p}_{f}(z)\right)$ is 5.42 per cent, while $\delta_{f}\left(\tilde{p}_{25 / 75}(z)\right)$ is 4.92 per cent. We observe, however, for all climate scenarios that the standard deviation of $\delta_{c}\left(p_{c-1}(z)\right)$, or, respectively, $\delta_{c}\left(\tilde{p}_{c-1}(z)\right)$, is bigger than the standard deviation of $\delta_{c}\left(p_{c}(z)\right)$. For the insured, this implies that insuring with non-adjusted contracts is more risky compared to hedging with an adjusted contract.

While expected profits from non-adjusted profit-maximising contracts are positive (in the medium and future scenario, for certain indices), they are significantly smaller than the profits from offering adjusted profit-maximising contracts. Non-adjusted profit-maximising contracts in the future scenario generate profits of $13.8-46.4 \mathrm{CHF} /$ ha, which reflects approximately the expected profits in today's conditions. By offering an adjusted contract, the insurer could generate profits that are three times higher. $\Pi_{f}\left(p_{f}(z)\right)$ ranges between 88.2 and $163.3 \mathrm{CHF} /$ ha. The standard deviation for all non-adjusted contracts is also quite large compared to the standard deviation of the adjusted contracts. Thus, offering non-adjusted contracts is more risky than offering adjusted profit-maximising contracts.

To sum up, evaluating the effect of hedging with non-adjusted insurance contracts for the insured revealed that non-adjusted contracts exist that generate higher hedging benefits than their adjusted counterparts in certain scenarios (medium and strong), but may make the insured worse off in others (future). In some cases, insuring with nonadjusted contracts may make the insured even worse off than in the situation without insurance (moderate).

We show that non-adjusted contracts that generate a higher hedging effectiveness than their adjusted contracts are not going to be offered by the insurer as these contracts create losses. Similarly, for the situation where expected profits from nonadjusted contracts are higher than profits from adjusted contracts (moderate), an evaluation of the hedging effectiveness shows that these contracts (based on Indices 1, 2 and 3) produce a negative $\delta$. These contracts would re-distribute wealth from the insured to the insurer and the insured would not buy them. As a result, insurers may not be able to sell non-adjusted weather insurance contracts any longer.

Focusing on non-adjusted contracts that produce simultaneously positive profits and hedging benefits, we find that the insurer (and the insured) could be better off with an adjusted profit-maximising contract (optimal contract), because these contracts generate on average similar expected profits (expected $\delta$ ) at a lower standard deviation. By not adapting weather insurance contracts on time, insurers face the risk of huge losses (as in the strong scenario) and the risk reduction for the insured is no longer guaranteed (as in the moderate scenario).

\section{Conclusion and outlook}

We shed light on the consequences of using historical data for designing and pricing weather insurance products for the resulting hedging effectiveness for the insured and 
the profitability for insurers. The objective of this paper is twofold: first, we evaluate the potential of using weather insurance to manage the climate change induced increase in weather risk. We simulate adjusted weather insurance contracts for today's and future climatic conditions using an insurance model developed by Kapphan. ${ }^{21}$ Adjusted insurance contracts are developed using weather data that represents the weather risk to be hedged. We find that the payoff function of adjusted contracts changes its shape over time, and that adjusted contracts are defined over a wider range of so far unprecedented realisations of the weather index. For stylised (linear) weather derivatives, our findings imply that insurance parameters (strike level, tick size and cap) have to be adjusted over time to effectively hedge future weather risk.

We show that the increase in weather risk due to climate change generates a huge potential for the weather insurance industry. In particular, we find that the insurance industry can expect profits to increase by up to 240 per cent (depending on the contract) when offering adjusted contracts. At the same time, the benefits in terms of risk reduction from hedging with adjusted weather insurance contracts almost triple for the insured.

Second, we analyse the effect of offering non-adjusted risk management products to cope with the expected increase in weather risk in light of climate change, that is we take into account that the insurance industry prices and designs contracts using historical (backward-looking) data, despite the fact that the stationarity assumption is no longer valid. We demonstrate that the payoff function of weather insurance products requires regular updating in times of climate change in order to guarantee that the product delivers the expected hedging benefits. Otherwise, we find that nonadjusted contracts either create substantial losses, or that profits from non-adjusted contracts are substantially smaller than profits from the corresponding adjusted contracts. While increasing the premiums of today's insurance products helps insurers to build up liquidity that can be used to cover the increase in future indemnities, this is not sufficient in order to provide clients with adequate risk management products. In contrast to damage-based insurance products, parametric insurance products require in addition that contract characteristics are regularly adapted in light of climate change.

Our results are driven by the changes in the distribution of the underlying weather index. These changes affect the frequency and extent of payments. Adjusted insurance contracts account for the new climatic conditions by providing higher payments at a higher frequency and in return charge a higher premium. With non-adjusted contracts, we observe that (depending on the index and the climatic conditions), the insured is either over- or under-compensated relative to the payments needed to cover the actual loss. The different patterns in which payout probabilities of non-adjusted contracts change (relative to the adjusted contracts), cannot be attributed to particular climatic conditions, since multi-peril weather indices were used to predict crop yields. More research is required to analyse how climate change affects the risk reduction derived from univariate weather indices, and how to best adapt (simple) insurance contracts.

Our results have been derived by studying the effect of a single climate change scenario on one crop at one geographical location. Future research should extend the methodology outlined in this paper to other crops and other regions using multiple 
climate projections to assess the effect of climate change on insurance design and risk reduction. The use of a process-based crop simulation in combination with climate projections represents one possible method for dealing with non-stationary yield data. In future work, statistical methods for dealing with non-stationary time-series data should be used to replicate our approach for evaluating the effect of hedging with nonadjusted insurance contracts.

Climate change projections are informed by General Circulation Models (GCM) and Regional Circulation Models (RCM), which are subject to uncertainty due to a number of factors such as the representation of the physical system, or the future boundary conditions that depend on the global economic development. From a risk management perspective, the state-of-the-art knowledge on generating local climate change projections should be used to determine the effect of uncertainty in anthropogenic warming estimates on our results, that is the effect of emission scenario uncertainty, as well as GCM/RCM model uncertainty on the simulated insurance contract, and, respectively, the effect of the uncertainty on the hedging effectiveness.

These uncertainties propagate to the crop model, which is subject to uncertainties in itself. Model uncertainties cannot be completely removed by calibration. However, after judicious set-up of the model parameters, crop models are generally in the position to simulate the most important direct interactions between climate and crops, as shown for example by Torriani et al. and Klein et al. ${ }^{54}$ While this does not ensure that a crop model is able to evaluate the impact of future climate conditions in an equally reliable manner, testing of the model under different climatic regimes for current conditions may provide confidence that model predictions outside the climatic boundaries of a specific location may not be completely unrealistic.

The performance of CropSyst with respect to the growing conditions across Switzerland has been widely demonstrated in the past by Torriani et al. and Finger and Schmid and Finger and Calanca. ${ }^{55}$ The work of Klein et al. ${ }^{56}$ further provides indications that CropSyst can properly deal with an increasing incidence of drought, as projected for Switzerland by the selected climate scenario. Specifically it was found in this investigation that CropSyst was able to realistically reproduce the yield decline caused by the summer heat wave of $2003^{57}$ at Payerne, a location in Northwest Switzerland that is prone to water deficits already under current climatic conditions. Finally, studies by other authors ${ }^{58}$ also support the view that crop models do provide adequate tools for studying the incidence of increasing climate variability on crop yields.

There remain nevertheless open questions concerning a possible increasing incidence of pests and diseases, and the effect of elevated atmospheric $\mathrm{CO}_{2}$ concentrations, both of which were not addressed in our study. Future work should more systematically investigate how sensitive the derived weather indices are to uncertainties in climate

\footnotetext{
${ }^{54}$ Torriani et al. (2007b), Klein et al. (2011).

${ }^{55}$ Torriani et al. (2007b), Finger and Schmid (2008), Finger and Calanca (2011).

${ }^{56}$ Klein et al. (2011).

${ }^{57}$ Schär et al. (2004).

${ }^{58}$ Asseng et al. (2011); Semenov and Shewry (2011).
} 
projections, crop model parameters and model assumptions. This will provide the basis for assessing uncertainties in the hedging effectiveness of adjusted contracts.

\section{References}

Asseng, S., Foster, I. and Turner, N. (2011) 'The impact of temperature variability on wheat yields', Global Change Biology 17(2): 997-1012.

Association of British Insurers (ABI) (2009) Financial risks of climate change: Examining the financial implications of climate change using climate models and insurance catastrophe risk models, ABI Research Paper, No.19.

Barnett, B. and Vedenov, D. (2004) 'Efficiency of weather derivatives as primary crop insurance instruments', Journal of Agricultural Research Economics 29(3): 387-403.

Beniston, M. (2003) 'The heatwave in Europe: A shape of things to come? An analysis based on Swiss climatological data and model simulations', Geophysical Research Letters 31(2): L02202.

Berg, A., Quirion, P. and Sultan, B. (2009) 'Can weather index drought insurance benefit to least developed countries farmers? A case study on Burkina Faso', Weather, Climate and Society 1(1): 71-84.

Bindi, M., Moriondo, M. and Giannakopoulos, C. (2010) 'Climate change impact assessment: The role of climate extremes in crop yield simulations', Climatic Change 104(3-4): 679-701.

Bresch, D., Bisping, M. and Lemcke, G. (2000) 'Storm over Europe: An underestimated risk', Swiss Re 09/2011.

Breustedt, G., Bokusheva, R. and Heidelbach, O. (2008) 'Evaluating the potential of index insurance schemes to reduce crop yield risk in an arid region', Journal of Agricultural Economics 59(2): 312-328.

Chen, C., McCarl, B. and Schimmelpfennig, D. (2004) 'Yield variability as influenced by climate: A statistical investigation', Climatic Change 66(1-2): 239-261.

Christensen, J. and Christensen, O. (2007) 'A summary of the PRUDENCE model projections of changes in European climate by the end of this century', Climatic Change 81(1): 7-30.

Clemo, K. (2008) 'Preparing for climate change: Insurance and small business', The Geneva Papers on Risk and Insurance-Issues and Practice 33(1): 110-116.

Deschenes, O. and Greenstone, M. (2007) 'The economic impacts of climate change: Evidence from agricultural output and random fluctuations in weather', American Economic Review 97(1): 354-385.

Dlugolecki, A. (2008) 'Climate change and the insurance sector', The Geneva Papers on Risk and InsuranceIssues and Practice 33(1): 71-90.

Finger, R. and Calanca, P. (2011) 'Risk management strategies to cope with climate change in grassland production: An illustrative case study for the Swiss plateau', Regional Environmental Change 11(4): 935-949.

Finger, R., Hediger, W. and Schmid, S. (2011) 'Irrigation as adaptation strategy to climate change-A biophysical and economic appraisal for Swiss maize production', Climatic Change 105(3-4): 509-528.

Finger, R. and Schmid, S. (2008) 'Modeling agricultural production risk and the adaptation to climate change', Agricultural Finance Review 68(1): 25-41.

Fischer, E. and Schär, C. (2010) 'Consistent geographical patterns of changes in high-impact European heatwaves', Nature Geoscience 3: 398-403.

Hawker, M. (2007) 'Climate change and the global insurance industry', The Geneva Papers on Risk and Insurance-Issues and Practice 32(1): 22-28.

IPCC (2001) Climate Change 2001: The Scientific Basis, Cambridge: Cambridge University Press.

IPCC (2007) Climate Change 2007: Fourth Assessment Report of the Intergovernmental Panel on Climate Change, Cambridge, United Kingdom and New York, NY, USA: Cambridge University Press.

Isik, M. and Devadoss, S. (2006) 'An analysis of the impact of climate change on crop yields and yield variability', Applied Economics 38(7): 835-844.

Kapphan, I. (2011) Weather insurance design with optimal hedging effectiveness, MPRA Paper, No. 35861.

Kapphan, I., Calanca, P. and Holzkaemper, A. (2011) Climate change, weather insurance design, and hedging effectiveness, IED Working Papers, No.17, ETH Zurich.

Klein, T., Calanca, P., Holzkaemper, A., Lehmann, N., Roesch, A. and Fuhrer, J. (2011) 'An efficient crop model calibration procedure for use with farm accountancy data', submitted to Agricultural Systems. 
316

Lazzarotto, P., Calanca, P., Semenov, M. and Fuhrer, J. (2010) 'Transient responses to increasing $\mathrm{CO}_{2}$ and climate change in unfertilized grass-clover mixtures', Climatic Research 41: 703-724.

Leblois, A. and Quirion, P. (2011) Weather-index drought insurance for millet growers in Niger: An ex-ante evaluation, Working Paper.

Lloyds of London (2006) 360 Risk Project: Climate Change Adapt or Bust, Lloyds, from http://www .lloyds.com $/ 360$.

Maynard, T. (2008) 'Climate change: Impacts on insurers and how they can help with adaptation and mitigation', The Geneva Papers on Risk and Insurance - Issues and Practice 33(1): 140-146.

McCarl, B., Villavicencio, X. and Wu, X. (2008) 'Climate change and future analysis: Is stationarity dying?' American Journal of Agricultural Economics 90(5): 1242-1247.

Mearns, L., Rosenzweig, C. and Goldberg, R. (1992) 'Effect of changes in interannual climatic variability on CERES-wheat yields: Sensitivity and $2 \mathrm{CECO}_{2}$ general circulation model studies', Agricultural Forest Meteorology 62(3-4): 159-189.

Meehl, G. and Tebaldi, C. (2004) 'More intense, more frequent, and longer lasting heatwaves in the $21 \mathrm{st}$ century', Science 305(5686): 994-997.

Mills, E. (2005) 'Insurance in a climate of change', Science 309(5737): 1040-1043.

Mills, E. (2009) 'A global review of insurance industry responses to climate change', The Geneva Papers on Risk and Insurance-Issues and Practice 34(3): 323-359.

Milly, P., Betancourt, J., Falkenmark, M., Hirsch, R., Kundzewicz, Z., Lettenmaier, D. and Stouffer, R. (2008) 'Stationarity is dead: Whither water management?' Science 319(1): 573-574.

Munich Re (2005) Weather Catastrophes and Climate Change, Munich, Germany: Munich Reinsurance Company.

Musshoff, O., Odening, M. and Xu, W. (2009) 'Management of climate risk in agriculture: Will weather derivatives permeat?' Applied Economics 43(9): 1067-1077.

Nakicenovic, N., Alcamo, J., Davis, G., de Vries, B., Fenhann, J., Gaffin, S., Gregory, K., Grbler, A., Jung, T., Kram, T., La Rovere, E., Michaelis, L., Mori, S., Morita, T., Pepper, W., Pitcher, H., Price, L., Raihi, K., Roehrl, A., Rogner, H., Sankovski, A., Schlesinger, M., Shukla, P., Smith, S., Swart, R., van Rooijen, S., Victor, N. and Dadi, Z. (2000) IPCC Special Report on Emissions Scenarios, Cambridge: Cambridge University Press.

Olesen, J. and Bindi, M. (2002) 'Consequences of climate change for European agricultural productivity, land use, and policy', European Journal of Agronomy 16(4): 239-262.

Reilly, J., Graham, J., Abler, D., Darwin, R., Hollinger, S., Izaurralde, C., Jagtap, S., Jones, J., Kimble, J., McCarl, B., Mearns, L., Ojima, D., Paul, E., Paustian, K., Riha, S., Rosemberg, N., Rosenzweig, C. and Tubiello, F. (2002) Changing Climate and Changing Agriculture: Report of the Agricultural Assessment Team, Cambridge: Cambridge University Press.

SBV (2010) 'Statistische Erhebungen und Schätzungen über Landwirtschaft und Ernährung', Schweizer Bauernverband (SBV, Swiss Farmers' Union), Brugg, Switzerland.

Schär, C. and Jendritzky, G. (2004) 'Hot news from the summer 2003', Nature 432(2): 559-560.

Schär, C., Vidale, P., Luethi, D., Frei, C., Haeberli, C., Liniger, M. and Appenzeller, C. (2004) 'The role of increasing temperature variability in European summer heatwaves', Nature 427(22): 332-336.

Schlenker, W. and Roberts, M. (2009) 'Nonlinear temperature effects indicate severe damages to U.S. crop yields under climate change', Proceedings of the National Academy of Sciences 106(37): 15594-15598.

Semenov, M. and Shewry, P. (2011) 'Modeling predicts that heat stress, not drought, will increase vulnerability of wheat in Europe', Nature Scientific Reports 1(66).

Semenov, M.A. and Barrow, E.M. (1997) 'Use of stochastic weather generator in the development of climate change', Clilmate Change 35(4): 397-414.

Stöckle, C.O., Donatelli, M. and Nelson, R. (2003) 'CropSyst-A cropping systems simulation model', European Journal of Agronomy 18(3-4): 289-307.

Stott, P., Stone, D. and Allen, M. (2004) 'Human contribution to the European heatwave of 2003', Nature 432: 610-614.

Torriani, D., Calanca, P., Beniston, M. and Fuhrer, J. (2007a) Alternative hedging strategies in maize production to cope with climate variability and change, Paper prepared for the 101. EAAE Seminar 'Management of Climate Risk in Agriculture'. 
Torriani, D., Calanca, P., Schmid, S., Beniston, M. and Fuhrer, J. (2007b) 'Potential effects of changes in mean climate and climate variability on the yield of winter and spring crops in Switzerland', Climatic Research 34(1): 59-69.

Vidale, P., Lüthi, D., Frei, C., Seneviratne, S. and Schär, C. (2003) 'Predictability and uncertainty in a regional climate model', Journal of Geophysical Research 108(4586): 12-23.

Ward, R., Herweijer, C., Patmore, N. and Muir-Woods, R. (2008) 'The role of insurers in promoting adaptation to the impacts of climate change', The Geneva Papers on Risk and Insurance-Issues and Practice 33(1): 133-139.

WMO (2011) WMO Statement on the Status of the Global Climate in 2010, WMO-No. 1074, Geneva, Switzerland: World Meteorological Organization.

Wuest, M., Bresch, D. and Corti, T. (2011) 'The hidden risk of climate change: An increase in property damage from soil subsidence in Europe', Swiss Re 07/11.

\section{About the Authors}

Ines Kapphan studied at the Swiss Federal Institute of Technology (ETH) and was a Visiting Researcher at the Stanford Institute for Economic Policy Research (SIEPR). She holds a Master's degree in Economics from the University of Konstanz, and a Master in Public Policy from The Fletcher School. Her research interests include the management of weather induced output volatility and micro-weather insurance solutions for adaptation to climate change.

Pierluigi Calanca holds a PhD in Natural Sciences/Climatology from the Swiss Federal Institute of Technology (ETH), Zurich. Since 2000, he has been a Senior Research Scientist at Agroscope Reckenholz-Tänikon (ART). His work is mainly concerned with climate change impacts and his activities range from the application of statistical methods to climate information to the development of ecosystem models. He has been involved in several national and international research programmes and is member of various international societies.

Annelie Holzkaemper is a Researcher working at Agroscope, the Federal Research Station for Agriculture in Switzerland. Her main research areas are climate impact studies for agroecosystems and the development of model-based decision-support tools for integrated resource management. She has a $\mathrm{PhD}$ from the Department of Computational Landscape Ecology at the Centre for Environmental Research in Leipzig, Germany in the field of environmental modelling. 